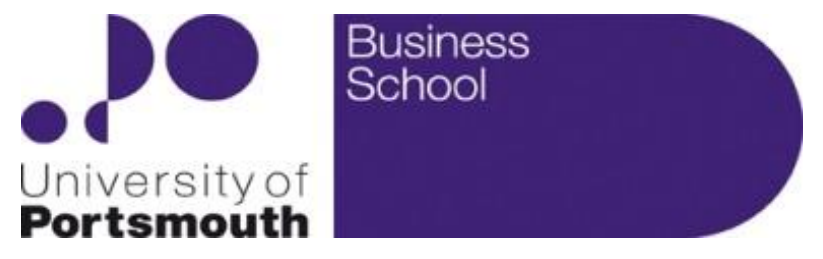

Working Papers in Economics \& Finance 2017-06

\title{
Liquidity Withdrawal in the FX Spot Market: A Cross-Country Study Using High-Frequency Data
}

Alexis Stenfors, Portsmouth Business School Masayuki Susai, Nagasaki University 


\title{
Liquidity Withdrawal in the FX Spot Market: A Cross-Country Study Using High-Frequency Data
}

\author{
Alexis Stenfors ${ }^{* *}$ and Masayuki Susai*
}

31 May 2017

\begin{abstract}
This paper studies the frequency and speed of limit order cancellations in the FX spot market for three categories of currency pairs. The first category includes the three most actively traded currency pairs (EUR/USD, USD/JPY and EUR/JPY), which have been at the forefront of algorithm trading. The second category includes two smaller G10 currency pairs (EUR/SEK and EUR/NOK) and the third category (USD/MXN, USD/RUB and USD/TRY) includes three of the most actively traded emerging market currencies. By investigating both market-specific and order-specific drivers of liquidity withdrawal, we report several findings that could serve to question traditional market microstructure theory as well as conventional 'market wisdom' with regards to trading behaviour on electronic trading platforms.
\end{abstract}

JEL Classification Numbers: D4, F3

Keywords: market microstructure, limit order book, foreign exchange, high-frequency trading, algorithmic trading

\footnotetext{
**A Alexis Stenfors (corresponding author), Portsmouth Business School, University of Portsmouth, Richmond Building, Portland Street, Portsmouth PO1 3DE, UK. Telephone: +44 (0)23 9284 4183. Email: alexis.stenfors@port.ac.uk

"Masayuki Susai, Nagasaki University, 4-2-1, Katafuchi, Nagasaki, 850-8506 Japan. E-mail: msusai@nagasaki-u.ac.jp
} 


\section{Introduction}

Algorithmic trading makes up an increasingly large share of the $\$ 5.1$ trillion-a-day turnover in the global foreign exchange (FX) market. Although no precise figures are available, it is estimated that around $25 \%$ of the FX spot market is done by algorithmic traders (King and Rime, 2010). Whereas proponents of algorithmic trading generally highlight benefits in terms of efficiency, competition, liquidity and hence lower transaction costs and an enhanced price discovery process (see, for instance, Bershova and Rakhlin, 2013; Broogard et al., 2014; Conrad et al., 2015; Stoll, 2014), the development is not without controversy. Some critics point out that algorithmic traders, and high-frequency traders in particular, by being able to react and anticipate order flow faster, ultimately 'crowd out' the liquidity traditionally provided by human traders at market making banks. At the worst, algorithmic traders could engage in market manipulative practices (such as spoofing and layering), which would be harmful to investors and reduce the quality of the market. Spoofing involves, after all, a submission as well as a cancellation of a limit order with the intent to mislead the market.

Although the vast majority of the research so far has been conducted on stock markets, empirical studies and surveys suggest that algorithmic trading in the FX markets has resulted in similar outcomes as in other financial markets: tighter bid-ask spreads, higher turnover, a larger number of (small) orders and a reduction in the average life-time of orders (BIS, 2011; Susai and Yoshida, 2015; Yeo, 2005). Overall, it appears as if algorithmic traders have contributed to better market liquidity in a range of markets, at least during periods of stability. However, by reacting very fast to new information, including to new orders submitted by others, markets largely populated with algorithmic traders have also become susceptible to a withdrawal of liquidity at an unprecedented speed and scale (Fong and Liu, 2010; Foucault et al., 2005). Indeed, as Rime (2011) and numerous market participants point out, better market liquidity has had a tendency to be accompanied by an 'illusion of liquidity' or a 'liquidity mirage'. The aim of this paper is to empirically investigate the drivers of the speed and frequency of limit order cancellations. 
Given that the FX market, in contrast to the stock market, is over-the-counter (OTC), largely unregulated and free from circuit breakers, it could be argued that it is more prone to systemic risks. In this respect, liquidity withdrawal en masse could act as an 'amplifying mechanism' (BIS, 2017) and, due to the inherently international nature of the FX market, have a more devastating impact on the global financial system (BIS, 2011; Harris, 2013). With central banks increasingly resorting to electronic trading platforms such as the Electronic Broking System (EBS) for currency interventions (Vitale, 2006), the traditional FX trading relationship between central banks and banks is going through a fundamental change. Moreover, following the revelations of widespread manipulation and collusive behaviour in the FX spot market (see, for instance, CTFC, 2014), the market making function performed by human traders is likely to remain under intense scrutiny by regulators and compliance officers alike. By studying liquidity withdrawal in a range of currency pairs under relatively stable market conditions, this paper aims to contribute not only to the literature on FX market microstructure, which, due to lack of data, hitherto has featured a relatively limited number of contributions on algorithm trading and high-frequency trading but also add to the on-going debate on currency interventions and the effective regulation of OTC markets.

Having gained access to high-frequency dataset provided by EBS (the most widely used electronic trading platform among market-making banks) from 9-13 September 2010, the purpose of this paper is to empirically investigate the withdrawal of liquidity from the FX spot market. Although the share of algorithmic trading on EBS rose from 2\% in 2004 to around 50\% in 2010, anecdotal evidence and surveys among banks suggest that the change has been most visible among the major currency pairs. Whereas medium-sized currency pairs also have seen an influx of algorithm trading, the vast majority of the small currencies are still reliant on the market making function provided by human traders at banks (King and Rime, 2010; BIS, 2011). However, anecdotal evidence from market participants indicates that some major emerging market currency pairs have witnessed a rapid transformation from human towards algorithmic trading in recent years.

To capture these changes, we study three categories of currency pairs. The first category includes the three most actively traded currency pairs (EUR/USD, USD/JPY 
and EUR/JPY), which, due to the extremely large turnover, have been at the forefront of algorithm trading. The second category includes two smaller G10 currency pairs (EUR/SEK and EUR/NOK. According to BIS (2013), the Swedish krona and the Norwegian krone were ranked $11^{\text {th }}$ and $14^{\text {th }}$ in terms of market turnover in 2013 . The third category (USD/MXN, USD/RUB and USD/TRY) includes three of the most actively traded emerging market currencies in two different time zones: the Mexican peso, the Russian rouble and the Turkish lira. All three have seen a phenomenal growth in turnover during the last $10-15$ years and were ranked $8^{\text {th }}, 12^{\text {th }}$ and $16^{\text {th }}$ in terms of global FX turnover in 2013 (BIS, 2013). Studying both 'market-specific' and 'order-specific' variables as potential causes for the speed and frequency of limit order cancellations, we report several findings that could serve to challenge traditional market microstructure theory, as well as conventional 'market wisdom' with regards to trading behaviour on electronic trading platforms.

The paper is structured as follows. Section 2 provides a brief overview of the related literature. Section 3 describes the data used. Section 4 outlines the model and the empirical results are discussed in Section 5. Following the results using the base model, the results using an extended model is discussed in Section 6. Section 7 concludes.

\section{Related Literature}

The market microstructure literature on order cancellations, or liquidity withdrawal more generally, is surprisingly thin. To some degree, this can be logically explained. A cancellation or a withdrawal implies, per definition, that a trade has not been done. Why, then, study decisions surrounding 'inaction' in financial markets? However, the topic is by no means new among financial market participants. A new limit order submission does not only involve the choice of price and amount, but also an assessment of the state of the market - including the market reaction to the limit order submitted. A possible reaction is, naturally, an almost withdrawal of liquidity by others (i.e. a string of limit order cancellations). Likewise, a trader having submitted a limit order not only watches the overall state of the market in relation to that 
particular order, but might also react to changes in the order book by cancelling and, perhaps, resubmitting the limit order.

However, the dynamics of limit order books is not only of relevance to market participants. It is also of interest to central bankers and regulators and has arguably become more urgent following the rise of algorithmic (and high-frequency) trading. A flash crash, for instance, is not only associated with sudden and violent price moves but also by a rapid disappearance of liquidity, permitting or triggering transactions to take place at prices outside a trading range that would otherwise be considered as 'normal'. The Flash Crash of 2010 or the Pound Flash Crash in October 2016 is, of course, extreme examples. However, an unexpected event in the form of a surprise central bank announcement or currency intervention may also lead to a sudden withdrawal of liquidity. ${ }^{1}$ Typically, the impact of such events on the market liquidity tends to be temporary. However, if market makers become less confident in their ability to not only supply but also demand instant liquidity, overall market quality may suffer in the long run. Thus, as order cancellations, regardless of their underlying causes, affect market liquidity (or the perception of it), the issue of liquidity withdrawal is of particular importance in OTC markets such as FX, which rely on voluntary market making - a function traditionally performed by commercial banks, but increasingly populated by high-frequency traders.

As the FX spot market for major (but also minor) currency pairs undergo a gradual migration to electronic platforms such as EBS and see a vast influx of algorithmic trading in the process, the traditional market making function by human traders is inevitably been challenged. Whereas this, on the one hand, could be seen as long overdue and beneficial for the liquidity and the price discovery process in the world's largest financial market, it also raises some important questions in terms of the systemic risks. In this respect, the FX market is no different from the exchange-traded securities market. Rather, the importance lies in the distinction between the market maker and market taker function. In the FX market, the former role was (and still is in the majority of currencies and instruments) held almost exclusively by a relatively small group of large banks. Whereas some more formal market making obligations

\footnotetext{
${ }^{1}$ For a good summary of recent events involving sharp intraday moves in the FX market, see BIS (2017).
} 
exist for some currency pairs (often with the endorsement of the respective central banks), the arrangements are largely bilateral and informal. However, as Stenfors (2017) notes, such as informal agreements can be remarkably stable if market makers feel a long-term 'sense of duty' towards the bank, its clients and its competitors - in other words, the market as a whole - with regards to the liquidity provision. This is consistent with the survey-based conducted by Cheung and Wong (2000) and Cheung and Chinn (2001), where a majority of FX dealers are found to rely on informal market conventions when determining bid-ask spreads - and that the maintenance of equitable and reciprocal trading relationships is central to such behaviour. Despite the rise in algorithmic trading, as well as the greater scrutiny imposed on market makers in the FX market following a string of manipulation scandals, such informal market making requirements remain important. Indeed, ACI (The Financial Markets Association), which for over half a century has acted as the trade organisation for banks and central bank dealers in the FX and money markets around the world, continues to stress their relevance as follows: '[...] bilateral reciprocal dealing relationships are common in the OTC markets and often extend to unwritten understandings between Dealers to quote firm two-way dealing prices' (ACI, 2015, p. 103-104). ACI sees the informal market making function by banks as logical and something that ought to be encouraged to maintain to maintain trust, reciprocity and liquidity in the marketplace.

Although the important role of order flow for exchange rate determination is well established in the literature (see, for instance, Lyons, 1997; Evans and Lyons, 2002; Bjønnes et al., 2005), the role of limit order cancellations remains an under-research topic not only in FX markets, but also in other liquid financial markets. In fact, traditional theoretical market microstructure models saw limit orders largely as passive trading strategies, whereby informed traders, instead, resorted to market orders (Glosten, 1994; Seppi, 1997). Hence, it could be argued that the withdrawal of liquidity among non-informed and passive traders would add minimal insight into the dynamics of exchange rates or market microstructure theory more generally. More recently, however, theoretical models have accounted for the ability of traders to choose between market orders and limit orders (Foucault, 1999; Parlour, 1998; Rosu, 2009). Seen from this perspective, traders are seen to actively consider whether to submit a market order or a limit order (which may, or may not, be executed). Even 
though a limit order submitted below [above] the prevailing best bid [ask] price in the market might be executed in due course (and hence turn out to be more advantageous than a market order), the strategy also contains risks. First, unless it becomes the best quote in the market, there is a risk that it might not be executed at all (Hasbrouck and Saar, 2002; Liu, 2009). This 'non-execution risk' might sometimes induce traders to cancel and resubmit their limit orders closer to the prevailing best bid-ask spread thereby increasing the probability of being hit by a market order. For instance, Fong and Liu (2010) find that larger and more aggressive limit orders on the Australian Securities Exchange are more likely to be revised or cancelled. Second, a limit order also contains 'free-option risk', i.e. the risk of being picked off by a trader with private information (Copeland and Galai, 1983). Thus, limit orders are associated with monitoring costs, as traders are constantly required to check the 'pulse' of the market in relation to the submitted limit orders (Fong and Liu, 2010; Liu, 2009).

Limit orders have been found not only to have become more prevalent in liquid financial markets but often become preferred as an active trading strategy (Foucault, 1999; Foucault et al., 2005; Rosu, 2009; Yeo, 2005). Indeed, more sophisticated technology and the rise of algorithmic trading has led to a dramatic increase in the number and proportion of limit order submissions. This development has been well documented, for instance on the Paris Bourse (Biais et al., 1995), on NYSE (Harris and Hasbrouck, 1996; Yeo, 2005), the Stockholm Stock Exchange (Hollifield et al., 2004) and on the Island ECN (Hasbrouck and Saar, 2002). Overall, it has resulted in a higher number and proportion of limit order cancellations and revisions, and a shortening of the lifetime of limit orders (see, for instance, Susai and Yoshida, 2014). It is no surprise that events involving violent and sudden price moves have been observed in financial markets increasingly dominated by electronic trading platforms. Trading algorithms cannot only be used to submit market and limit orders more frequently and more rapidly. They can also be used to withdraw limit orders more frequently and more rapidly. Thus, whereas the rise of algorithmic trading can be seen through the lens of limit order submissions (which has contributed to the increased liquidity provision in a range of financial markets), the opposite perspective can also be used. 
Our study puts the emphasis on the frequency and speed of limit order cancellations. Moreover, the approach differs significantly from previous studies on order cancellations and revisions. By focusing on the cumulative number of order cancellations within different time windows following each new limit order submission, we strive to capture the 'dual' nature of order cancelling behaviour. On the one hand, liquidity withdrawal may depend on a series of 'market-specific' variables that are independent of the order submission serving as the starting point for the calculation. We account for these factors by using proxies for market activity (Biais et al., 1995), market depth (Yeo, 2005), price volatility (Foucault, 1999) and the bid-ask spread (Biais et al., 1995; Foucault, 2007).

On the other hand, traders may also react differently depending on the characteristics of incoming orders to the market. To incorporate these 'order-specific' factors, we therefore also study variables linked to the strategic behaviour of the trader submitting the order. Here, we include the direction of the limit orders and various measures of price aggressiveness. For a selection of currency pairs, we also extend the model to account for the orders size and order-splitting strategies. When submitting a limit order, a trader also needs to select the appropriate aggressiveness and size of the order. Whereas a market order, per definition, is an aggressive order as the intention is to execute a trade immediately at the prevailing best market price, the probability of a limit order being executed is dependent on how far away it is submitted from the market price (see, for instance, Griffiths et al., 2000; Cao et al., 2004; Ranaldo 2004). However, as Lo and Sapp (2010) find, more aggressive limit orders in the FX market tend to be smaller in size, suggesting that there is a strategic trade-off between aggressiveness and size. A large limit order might be interpreted as market-moving and therefore trigger other traders to cancel their limit orders - thereby decreasing the likelihood of being filled. Indeed, several studies show that traders adopt ordersplitting strategies in attempts to disguise the 'true' size of the limit order, thereby allowing them to submit relatively more aggressive orders without having the corresponding negative impact on the liquidity of the market. Following the logic of Keim and Madhavan (1995, 1996), order-spitting strategies might be 'informed traders' as well as 'liquidity traders'. Whereas an informed trader would prefer to disguise his private information as signalled by a large order submission, a trader 
demanding liquidity would want to hide his 'full amount' to avoid front-running. ${ }^{2}$ In sum, high-frequency liquidity withdrawal is a multifaceted phenomenon and can stem from a multitude of sources. These can range from the overall state of the market at a particular moment in time to strategic limit order submission behaviour intended to achieve a trade execution at the best possible price - or perhaps even a trading strategy to assess the impact on liquidity provision by others.

\section{Data}

We use a high-frequency dataset from 21:00:00 (GMT) on 8 September 2010 to 20:59:59 (GMT) on 13 September 2010 (including the weekend) obtained from EBS, the most widely used electronic trading platform among market-making banks. As Table 1 shows, our study captures three trading days with low FX volatility. With a price range of approximately $1-2 \%$ for all currency pairs, the period ought to be suitable for a cross-country study under relatively comparable market conditions.

Table 1: Overview of the currency pairs

\begin{tabular}{lllll}
\hline Currency pair & Low & High & Range $(\%)$ & Total market daily turnover \\
\hline EUR/USD & 1.2643 & 1.2893 & $1.96 \%$ & $\$ 494,040,648,978$ \\
USD/JPY & 83.49 & 84.50 & $1.20 \%$ & $\$ 447,858,805,701$ \\
EUR/JPY & 105.965 & 107.94 & $1.85 \%$ & $\$ 109,310,494,623$ \\
\hline EUR/SEK & 9.1600 & 9.2540 & $1.02 \%$ & $\$ 14,177,892,189$ \\
EUR/NOK & 7.8456 & 7.9159 & $0.89 \%$ & $\$ 11,008,877,568$ \\
\hline USD/MXN & 12.7645 & 13.0557 & $2.26 \%$ & $\$ 54,169,517,444$ \\
USD/RUB & 30.64 & 30.97 & $1.07 \%$ & $\$ 34,969,683,713$ \\
USD/TRY & 1.4866 & 1.5204 & $2.25 \%$ & $\$ 13,931,439,112$ \\
\hline
\end{tabular}

Sources: EBS, BIS (2013) and authors' calculations. Notes: Market daily turnover = Daily average global turnover in the respective FX currency pair in April 2013 (in USD). 'Low' and 'high' denotes the lowest and highest mid-market limit order price during 9-13 September 2010.

On EBS, traders can either initiate a quote (i.e., submit a limit order) or match a posted quote (i.e., submit a market order). In the dataset we have acquired, all data entries are assigned one of five indicators (QS, QD, HS, HAD or DSM). A new limit order begins with QS (i.e., a limit order submission) and ends with QD (i.e., a limit order cancellation). A hit begins with HS and ends with HAD. When two counterparties are matched in a transaction on EBS, the information for the transaction is recorded as a DSM. A unique 20-digit Trader ID is attached to each

\footnotetext{
${ }^{2}$ On orders and order-splitting strategies, see, for instance: Pérold 1988; Engle et al., 2012; Chan and Lakonishok, 1995; Pérold 1988; Yeo, 2005.
} 
indicator, allowing us to match order submissions and order cancellations. However, the identities or institutions are not revealed.

Having filtered the dataset for limit order submissions and limit order cancellations only, and removed all new limit orders that do not have a corresponding cancellation within the same day (less than $0.005 \%$ of all limit order submissions), we are left with over 3 million limit orders submissions, worth more than $\$ 5$ trillion (see Table 2).

Table 2: Overview of limit order submissions

\begin{tabular}{lll}
\hline Currency pair & Number of limit order submissions & Total limit order amount \\
\hline EUR/USD & $1,419,630$ & $€ 1,818,803,000,000$ \\
USD/JPY & 787,213 & $\$ 1,020,022,000,000$ \\
EUR/JPY & 751,239 & $€ 897,039,000,000$ \\
\hline EUR/SEK & 47,473 & $€ 52,839,000,000$ \\
EUR/NOK & 36,063 & $€ 41,331,000,000$ \\
\hline USD/MXN & 127,833 & $\$ 234,397,000,000$ \\
USD/RUB & 31,778 & $\$ 212,680,000,000$ \\
USD/TRY & 38,499 & $\$ 38,704,000,000$ \\
\hline
\end{tabular}

Sources: EBS and authors' calculations.

For every single limit order submission, we calculate the number of limit buy and sell order cancellations, respectively, within pre-specified time windows. Given that computer algorithms have the ability to react faster than humans, we have chosen seven different time windows $(0.1,0.2,0.5,1,5,10,60$ seconds $)$ to investigate potential differences when allowing for human traders to have time to react - thus providing a deeper insight into the dynamics of the liquidity withdrawal process.

\section{The model}

We run a total of 112 regressions using the following model:

$$
\begin{aligned}
& \sum_{t(i)}^{t(i)+w} \operatorname{LOC}_{i}^{d}=\alpha_{i}+\beta_{1} A c t_{i}+\beta_{2} \operatorname{Dep}_{i}+\beta_{3} \operatorname{Vol}_{i}+\beta_{4} B A_{i}+\beta_{5} A g g_{i}+\delta_{1} O P P_{i}+\delta_{2} A 2_{i}+\delta_{3} A 3_{i}+ \\
& \delta_{4} A 4_{i}
\end{aligned}
$$

The dependent variable is the number of limit buy or sell order cancellations $\left(L O C^{d}\right)$, within a specified time window $(w)$, where $w=0.1,0.2,0.5,1,5,10$ or 60 seconds following a new limit order submission $\left(\operatorname{LOS}_{i}\right)$. Limit buy order cancellations are denoted as $L O C^{B}$ and limit sell order cancellations are denoted as $L O C^{S}$. 
The number of order cancellations might be influenced by a range of factors. Some henceforth referred to as 'market-specific' variables, relate to the market in which the orders are submitted and not (directly) related to the limit order submissions themselves. The other group, which we refer to as 'order-specific' variables, are included to capture the specific characteristics of the new limit order submissions (and more related to strategic trading), which might trigger more or fewer cancellations.

\subsection{Market-specific variables}

The main factor determining the number of limit order cancellations is, of course, the number of limit order submitted previously. We refer to this as 'market activity', where $A c t_{i}=\sum_{t(i)-60 s}^{t(i)} \operatorname{LOS}_{i}$, and as a proxy, we use the number of limit order submissions submitted to the EBS platform in the respective currency pair during the previous 60 seconds. A higher level of market activity should, ceteris paribus, result in a higher number of limit order cancellations.

The number of order cancellations might also depend on the depth of the market. We measure 'market depth' as the sum of the total amount $(A)$ of outstanding limit buy and sell orders at the best market bid $(b b)$ and ask $(b a)$ prices respectively, immediately prior to the limit order submission $i$. Hence, $\operatorname{Dep}_{i}=\sum_{t(0)}^{t(i-1)} A^{b b}+\sum_{t(0)}^{t(i-1)} A^{b a}$. A deeper market ought to trigger more order cancellations for two reasons. First, an increase in the depth on the same side of the market should trigger competing traders to cancel and resubmit their orders at more competitive price levels (Biais et al., 1985; Hall and Hautsch, 2006, 2007). Second, an increase in the depth on the opposite side of the market should increase the likelihood that traders cancel and resubmit their orders at a different price due to the expected change in the cost of transacting (Goettler et al., 2005; Lo and Sapp, 2010).

Given the extremely short time windows used in our estimation, we also apply a very short-term measure of volatility. Hence, 'volatility' is measured using the mid-market price of the best limit buy and sell orders $(\mathrm{bm})$ at each second during a 60-second interval prior to the new limit order submission, i.e. $\operatorname{Vol}_{i}=$ 
$\left.\left.\left.\sqrt{252 * 24 * 60 * \sigma\left(\sum_{t(i)-61 s}^{t(i)-1 s}\left(\left(p_{t(i)-1 s}^{b m}\right.\right.\right.} / p_{t(i)-2 s}^{b m}\right)-1\right)\right)$. Theoretically, higher short-term volatility should result in more order cancellations, as traders become more induced to reassess whether their orders are submitted at an appropriate price (and therefore cancel and resubmit their orders at different prices). This logic is similar to Foucault (1999) and Foucault et al. (2005), where price volatility is connected to a change in information asymmetry among market participants. However, it could also be argued that higher volatility increases the likelihood of orders being filled, thus acting to reduce the withdrawal of liquidity from the market.

Moreover, liquidity withdrawal could be a function of the market liquidity at the time. Here, we use the standard bid-ask spread, i.e. the difference between the best ask and bid prices, $\left(p_{t-1}^{b a}-p_{t-1}^{b b}\right)$ measured vis-à-vis the mid price, $p_{i-1}^{b m}$, on the EBS platform immediately prior to the limit order submission. Thus, $B A_{i}=\left(p_{t-1}^{b a}-p_{t-1}^{b b}\right) / p_{i-1}^{b m}$. The impact of the prevailing bid-ask spread on the number of order cancellations is not clear. On the one hand, a wide bid-ask spread might indicate uncertainty in the market (Foucault et al., 2007), thus acting to reduce the number of order submissions and cancellations. On the other hand, a wide bid-ask spread might induce traders to supply liquidity at better price levels, in other words, to cancel and improve the prices at which their limit orders are submitted (Lo and Sapp, 2010).

\subsection{Order-specific variables}

The order-specific independent variables are included to capture the strategic behaviour of traders submitting (and cancelling) limit orders.

'Price aggressiveness' of the limit order submission $i$, where $p_{i}$ denotes the limit order price, is measured vis-à-vis the mid price, $p_{i-1}^{b m}$ prior to the order submission: $A g g_{i}=\left|\left(p_{i}-p_{i-1}^{b m}\right)\right| / p_{i-1}^{b m}$. The variable takes a value between 1.0000 (if the order is submitted at the mid-market price) and 0.0000 (if the order is submitted at $1 \%$ or further away from the mid-price). ${ }^{3}$ A limit order submitted at an aggressive price should result in more limit order cancellations for two reasons. First, an aggressive

\footnotetext{
${ }^{3}$ By capping the price aggressiveness at $1 \%$, orders submitted very far away from the market and therefore extremely likely to be filled (such as at 0.00 or 9999.99) are less likely to bias the results.
} 
buy [sell] order should trigger some traders with sell [buy] orders to cancel their orders and, in anticipation of an advantageous market price move, resubmit them at a higher [lower] price. Second, an aggressive buy [sell] order should trigger some traders with buy [sell] orders to cancel their orders and, in anticipation of a disadvantageous market price move, resubmit them at a higher [lower] price.

However, when it comes to price aggressiveness, it is not only the distance to the midprice that matters. An order could be perceived to be particularly relevant to the market if it improves or matches the prevailing best bid-ask spread. To account for such order submissions, we also classify limit orders according to their price aggressiveness using a scale from 1 to 4 , where:

4 [very aggressive] $=$ if the new limit order submission price $p_{i}$ improves the best bid-ask spread $\left(p_{t-1}^{b a}-p_{t-1}^{b b}\right)$.

3 [aggressive] $=$ if the new limit order submission price $p_{i}$ matches the best bid-ask spread $\left(p_{t-1}^{b a}-p_{t-1}^{b b}\right)$.

2 [moderately aggressive] $=$ if the new limit order submission price $p_{i}$ is outside, but within 2 pips (200 pips for EUR/SEK, EUR/NOK and $\mathrm{USD} / \mathrm{MXN})^{4}$ of the best bid-ask spread $\left(p_{t-1}^{b a}-p_{t-1}^{b b}\right)$.

1 [not aggressive] $=$ if the new limit order submission price $p_{i}$ is more than 2 pips away from the best bid-ask spread $\left(p_{t-1}^{b a}-p_{t-1}^{b b}\right)$.

In the model we therefore also include dummy variables for orders that very aggressive (A4), aggressive (A3) or moderately aggressive (A2), and would expect the reaction to these to be stronger.

Finally, $O P P_{i}$, an 'opposite order' is a dummy variable for limit order submissions from the other side of the market. It is generally assumed that traders with private information takes into account the prevailing and future liquidity on the other side, as this is a key factor in determining the ability to execute large orders at a fair price. Consequently, traders are typically assumed to react to incoming large orders from the

\footnotetext{
${ }^{4}$ To account for market conventions and differences in currency values, we denote 1 pip as the $4^{\text {th }}$ decimal for EUR/USD, EUR/SEK, EUR/NOK, USD/MXN and USD/TRY and as the $2^{\text {nd }}$ decimal for USD/JPY, EUR/JPY and USD/RUB.
} 
other side by cancelling their orders (and then, perhaps, resubmitting their orders at a more favourable price to them). A somewhat similar logic could, however, also be applied to traders reacting to an incoming large order from the same side. As such a limit order might move the market away from them simply by being submitted, they, too, would be more inclined to cancel their orders (in order to resubmit and them at a rate closer to the best market price at the time). In our model, we account for such behaviour.

\subsection{Estimation and diagnostics}

For estimating the base model and the extended model (see Section 6), we use OLS. For robustness, we check the residual diagnostics, especially heteroscedasticity test. In these diagnostics, we use the Breusch-Pagan-Godfrey test. With the diagnostics of the residuals, we also estimate both models using a TOBIT regression (because the dependent variable in our model ranges from 0 to positive, it might better to use TOBIT). However, having checked and found no significant differences between the results using OLS (Tables 4-19 and 36-45) and TOBIT (Tables 20-35 and 46-55), we have opted for OLS. Further, the Breush-Pagan-Godfrey test tells us that the null hypothesis of no heteroskedasticity against heteroskedasticity is rejected in all estimations. Consequently, we use White heteroskedasticity-consistent standard errors and covariance in our estimations.

\section{Empirical Results}

\subsection{Dependent variable}

The estimation results are shown in Tables 4-19. The most striking, but perhaps not too surprising, result concerns the dependent variable: the number of limit order cancellations. Given the level of trading activity in the markets, and the number of limit order submission, the mean dependent variable is very high considering the relatively short time windows chosen. For instance, the EUR/SEK dataset contains 47,473 limit order cancellations. Assuming an equal number of buy and sell orders over three 24-hour trading days, this represents an average of 0.009 buy [sell] order 
cancellations per 0.1 seconds $^{5}, 0.092$ buy [sell] order cancellations per 1.0 seconds and 5.495 buy [sell] order cancellations per 60.0 seconds. However, as Table 10 shows, the mean dependent variable is considerably higher for the corresponding time windows: 0.298 [0.258] limit order cancellations within 0.1 seconds, 1.665 [1.554] within 1.0 seconds and 17.381 [14.253] within 60.0 seconds. A similar pattern is displayed for all currency pairs, regardless whether they are actively traded aroundthe-clock (EUR/USD, USD/JPY and EUR/JPY) or whether the trading activity is more concentrated within one specific time zone (EUR/SEK, EUR/NOK, USD/MXN, USD/RUB and USD/TRY).

However it is not the frequency of the cancellations, in itself, that stands out. Rather, it is the speed at which the extreme frequency decreases and then 'normalises'. If the number of limit order cancellations per 0.1 seconds are allocated an index of " 1 " during the 10-60 second period after each new limit order submission, we can work out the speed of this normalisation process. Figure 1 illustrates this phenomenon.

Figure 1: 'Normalisation process' of limit order cancellations

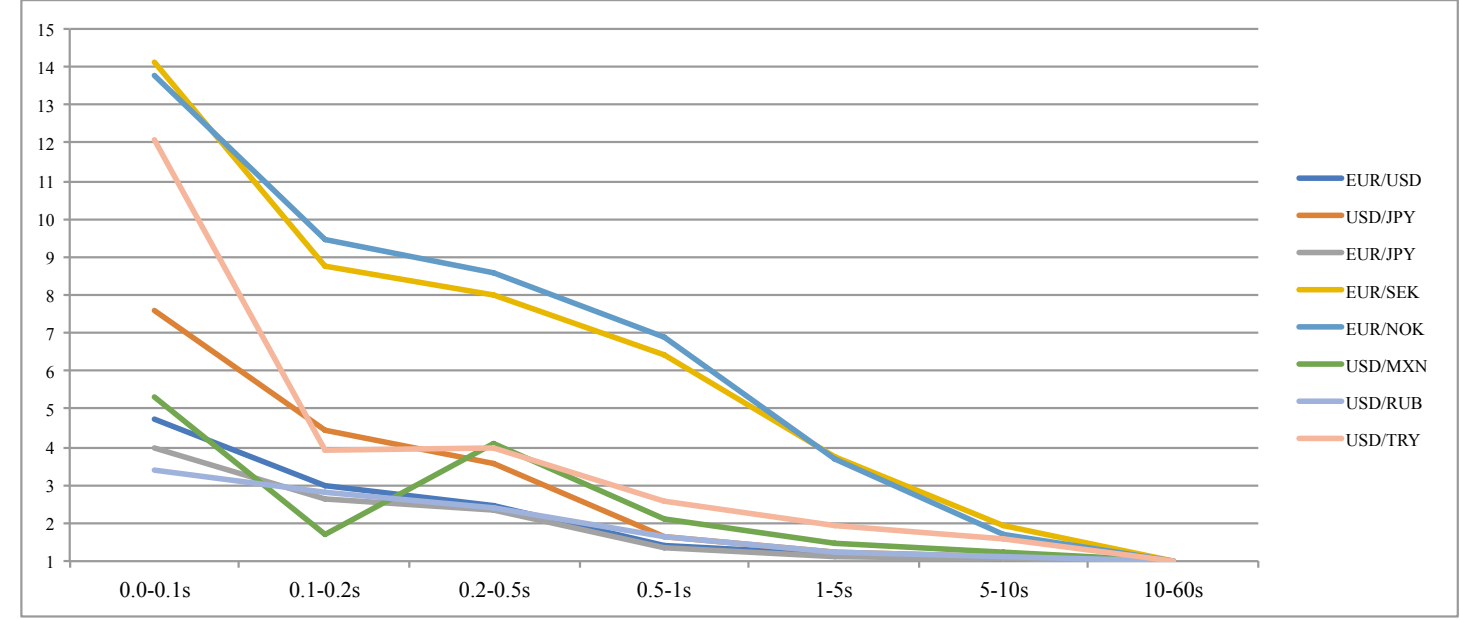

Sources: EBS and authors' calculations.

As can be seen, a new limit order submission in USD/JPY, for instance, is followed by, an average, 7.5 times more limit order cancellations within 0.1 seconds than 10-60 seconds after a new submission to the limit order book. However, after 0.1 seconds (but within 0.2 seconds), the cancellation frequency has already been reduced to 4.5 times and after 1 second, the process has more or less 'normalised'. Thus, it appears

\footnotetext{
${ }^{5} 47,473 / 2 /(3 * 24 * 60 * 60 * 10)=0.009$
} 
as if the frequency distribution of order cancellations in the FX spot market follows a power law, similarly to what has been observed in the size of equity orders for stock markets where high-frequency traders are prominent (see, for instance, Gopikrishnan et al., 2000; Maslow and Mills, 2001).

The liquidity withdrawal for all eight currency pairs is at its most extreme within a few hundred milliseconds (or "faster than a human can blink") of each new limit order submission. Once human traders plausibly could have had time to react, the cancellation frequency has all but normalised, and little change is observed between 1 and 60 seconds. Interestingly, however, the pattern for the Scandinavian currency pairs, EUR/SEK and EUR/NOK, is somewhat different. Although almost identical, the normalisation process is considerably slower than for all the other currency pairs.

\subsection{Market-specific variables}

As the empirical results in Tables 4-19 show, market activity is the logical (and main) driver of order cancellations for all currency pairs.

The sign of market depth is consistently positive (and significant) for EUR/USD, USD/JPY, EUR/JPY, EUR/SEK and USD/TRY for all time windows, and for EUR/NOK for most time windows. In other words, order cancellations in the markers are clearly positively correlated with the total amount of buy and sell orders submitted at the best bid and ask prices at the time of a new order submission. Interesting, however, the pattern in mostly the reverse for USD/MXN and USD/RUB. For these emerging market currency pairs, a thinner market triggers more cancellations.

The bid-ask spread is a consistently (negative) predictor of the number of order cancellations for the three major currency pairs (EUR/USD, USD/JPY and EUR/JPY) and USD/MXN. Put differently, the more liquidity is added to the market (in terms of tightening the bid-ask spread), the more liquidity is also withdrawn from the market. However, the pattern of liquidity withdrawal is different for the smaller currency pairs in terms of the bid-ask spread. For EUR/SEK and EUR/NOK, the spread has an overwhelmingly positive, rather than negative, impact. This is consistent with the findings of Lo and Sapp (2010), suggesting that a wide bid-ask spread could act as a 
trigger to submit, cancel and resubmit orders at gradually more aggressive prices. For USD/TRY, the impact is consistently negative in the very short-term (up to 0.5 seconds) but consistently positive when longer time windows are used (beyond 5 seconds). The results for USD/RUB are inconsistent or not significant.

Similarly, the impact of short-term volatility on the number order cancellations is consistent for the major currency pairs. Here, the sign is positive and significant. In other words, traders have a tendency to withdraw liquidity as volatility increases, along with the lines of Foucault (1999) and Foucault et al. (2005). However, for all other currency pairs, the relationship is mixed (positive, negative or insignificant) depending on the time window used.

\subsection{Order-specific variables}

Intuitively, we would expect traders to react faster and stronger to new orders submitted from the other side of the order book. If a buy [sell] initiative is more likely to lead to a higher [lower] price (see, Bjønnes et al., 2005), a limit buy [sell] order ought to cause more limit order cancellations on the opposite side as sellers [buyers] incorporate the new information and revise their expectations of the future price. This should cause more cancellations and, perhaps, resubmissions at a higher [lower] price. Traders on the same side also revise their expectations (and consequently cancel and resubmit their orders), but are, ceteris paribus, less likely to be picked off.

In this respect, the empirical results highly are interesting. On the one hand, when using very short time windows (0.1, 0.2 and 0.5 seconds), the relationship is often positive and strongly significant for EUR/USD, USD/JPY, EUR/JPY, USD/MXN and USD/RUB: a limit buy [sell] order triggers more limit sell [buy] order cancellations. On the other hand, the relationship is consistently the opposite when slightly longer time windows are used, in other words, a limit buy [sell] order triggers more limit buy [sell] order cancellations. This might appear counter-intuitive. However, as Biais et al. (1995) show, using data from the Paris Bourse, cancellations on the bid [ask] of the book tend to be more frequent following a market buy [sell] order. This could be due to the fact that traders can use market orders to check for hidden orders and the depth of the market on the opposite side - and then cancel their limit orders if it is found to 
be thin. The same logic could be applied to limit orders. By submitting and cancelling limit buy [sell] orders (and the resubmitting at a higher [lower] price) information can be extracted about the dynamics of the order book. Indeed, the relationship is negative for EUR/SEK, EUR/NOK and EUR/TRY for all time windows used, and the impact on the mean dependent variable is substantial.

Such strategic limit order submission behaviour might get support when studying the 'price aggressiveness' variable. Intuitively, we would expect traders to be more inclined to cancel and then, perhaps, resubmit orders when an aggressive (and potentially market-moving) enters the limit order book. At the same time, however, a less aggressive limit order submission is more likely to be cancelled and resubmitted at a more aggressive price. In this respect, the results for EUR/USD, USD/JPY and EUR/JPY paint a consistent picture supporting the second theory: the less price aggressive a new limit order is, the more limit order cancellations follow for time windows up to 10 seconds. However, for all the other currency pairs, price aggressiveness result in more and fewer order cancellations, depending on which time window is used and whether it is a buy or a sell order.

The dummy variables provide further insights into this behaviour. For EUR/USD, a new buy [sell] limit order submission has to improve the best bid [offer] in the market to trigger more cancellations, and even so, this relationship only holds for the 60second time window. For USD/JPY, the same holds for the $0.2,0.5$ and 1 second time windows, as well as orders that match the best bid [offer] price in the market for the 60-second time window. USD/MXN and USD/TRY, by contrast, are highly sensitive to very aggressive and aggressive orders, whereas the results for USD/RUB, EUR/SEK and EUR/NOK are more mixed.

\section{An extended model}

According to Lo and Sapp (2010), traders not only consider price aggressiveness when submitting limit orders but also the amount. Anecdotal evidence from traders strongly suggests that large orders are more likely to influence the market price (and hence more likely to trigger order cancellations) than small orders. Although our 
dataset contains some very large limit orders indeed, the overwhelming majority of is for precisely the minimum amount allowed on the electronic platform, namely $\$ 1$ million or $€ 1$ million (see Table 3). In fact, the proportion of minimum orders for EUR/SEK, EUR/NOK and USD/TRY is close to $100 \%$. A notable exception is the USD/RUB market, where larger orders are the norm, rather than the exception.

Table 3: Amounts and split orders

\begin{tabular}{lllll}
\hline Currency pair & Minimum & Maximum & Minimum $(\%)$ & Split orders $(\%)$ \\
\hline EUR/USD & $€ 1,000,000$ & $€ 250,000,000$ & $86.50 \%$ & $17.42 \%$ \\
USD/JPY & $\$ 1,000,000$ & $\$ 250,000,000$ & $85.41 \%$ & $20.44 \%$ \\
EUR/JPY & $€ 1,000,000$ & $€ 100,000,000$ & $88.63 \%$ & $25.25 \%$ \\
\hline EUR/SEK & $€ 1,000,000$ & $€ 1,000,000$ & $100.00 \%$ & $0.00 \%$ \\
EUR/NOK & $€ 1,000,000$ & $€ 2,000,000$ & $100.00 \%$ & $0.00 \%$ \\
\hline USD/MXN & $\$ 1,000,000$ & $\$ 10,000,000$ & $74.50 \%$ & $0.06 \%$ \\
USD/RUB & $\$ 1,000,000$ & $\$ 49,000,000$ & $2.32 \%$ & $1.77 \%$ \\
USD/TRY & $\$ 1,000,000$ & $\$ 3,000,000$ & $99.97 \%$ & $0.17 \%$ \\
\hline
\end{tabular}

Sources: EBS and authors' calculations.

To capture the potential impact of large orders, we use include dummy variable. $L_{i}$, a 'large limit order', is a dummy variable for order amounts larger than ( $\$$ or $€) 1$ million. A large limit order should, ceteris paribus, trigger more and faster limit order cancellations, as the amount is larger than the $\$ 1$ million or $€ 1$ million 'baseline limit order'.

However, as a result of the anticipated market reaction following a large order submission, a well-established (algorithmic) trading strategy is that of order-splitting. Assuming that other traders react more (and faster) to large limit orders, a string of relatively small order submissions could act to disguise the 'true' order size and hence trigger a more muted market reaction. Algorithmic traders have a greater ability than human traders to split large orders into many small orders. As consequence, a high number and proportion of very small orders is often observed in financial markets where such trading is prominent.

In our model, $S L O_{i}$, a 'split limit order', is a dummy variable. To be counted as a split order, all of the following four criteria need to hold. First, the price of limit order submission, $p_{i}$, is the same as the price of limit order, $p_{j}$, where $j \neq i$. Second, the direction of limit order submission $i$ (i.e. bid or ask) is the same as the direction of limit order submission $j$. Third, limit order $i$ and limit order $j$ are submitted within less than 0.1 seconds of each other. Fourth, no other orders are submitted or cancelled in 
between the submissions of limit order $i$ and limit order $j$. If an order-splitting strategy is used to conceal the 'true' (larger) order size, it should, ceteris paribus, have no impact on the subsequent number and speed of limit order cancellations. However, if the order-splitting strategy is detected by other traders, it should result in more order cancellations. Our classification of a split limit order is more conservative than that of Yeo (2005) on the stock market. Obviously, orders submitted within more than 0.1 seconds of each other or at different prices might still be part of an order-splitting strategy. However, given that our methodology already results in around $20 \%$ of all orders being classified as split limit orders in the EUR/USD, USD/JPY and EUR/JPY FX spot markets (see Table 3), we do not believe a less conservative measure is necessary to capture potential differences.

The empirical results for size and price aggressiveness of the limit order submissions would also benefit further investigation, as the variables cannot be analysed properly in complete isolation from each other. Indeed, Lo and Sapp (2010) find evidence of a trade-off between size and aggressiveness among orders submitted by traders in the FX spot market for US dollars against Deutschemarks and Canadian dollars in 1997 an observation which is also strongly supported by market participants. To be able to account for these factors, we restrict the extended model to currency pairs containing a sufficient number of split and large orders. These are EUR/USD, USD/JPY, EUR/USD, USD/MXN and USD/RUB. In the extended model, we include a series of dummy variables for split orders, as well as large orders that very aggressive $(A 4)$, aggressive $(A 3)$ or moderately aggressive $(A 2)$. We also use a dummy variable to capture the reaction to large limit orders submitted from the opposite side, and would expect the reaction to these to be stronger.

We then run another 70 regressions with an extended model as follows:

$$
\begin{aligned}
& \sum_{t(i)}^{t(i)+w} \operatorname{LOC}_{i}^{d}=\alpha_{i}+\beta_{1} A c t_{i}+\beta_{2} \mathrm{Dep}_{i}+\beta_{3} \mathrm{Vol}_{i}+\beta_{4} B A_{i}+\beta_{5} A g g_{i}+\delta_{1} O P P_{i}+\delta_{2} A 2_{i}+\delta_{3} A 3_{i}+ \\
& \delta_{4} A 4_{i}+\delta_{5} S L O_{i}+\delta_{6} O P P_{i} * L_{i}+\delta_{7} A 2_{i} * L_{i}+\delta_{8} A 3_{i} * L_{i}+\delta_{9} A 4_{i} * L_{i}
\end{aligned}
$$

The overall results from the extended model are fairly similar to those of the base model. Whereas the dummy variable for large orders from the opposite side of the 
order book does not seem alter the results markedly, the insights from the other orderspecific dummy variables and can be summarised as follows (see Tables 36-45).

Theoretically, as well as anecdotally, we should expect large and relatively aggressive limit order submissions to trigger more cancellations. Interestingly, our results indicate significant differences between the currency pairs, the level of price aggressiveness and the time windows used. The USD/MXN dataset consists of approximately $25 \%$ large orders. Large orders that are classified as either very aggressive, aggressive or moderately aggressive consistently trigger more order cancellations for time windows up to 1 second - precisely as we should expect. For USD/RUB, however, where large orders are the norm, rather than the exception (over $97 \%$ are classified as large orders), the relationship is highly unstable. Here, we are even unable to draw the conclusion that large orders submitted within the prevailing best bid-ask spread prompt more cancellations than normal. The results for the major currency pairs (EUR/USD, USD/JPY and EUR/JPY) are, however, relatively similar. For these, which contain around 10-15\% large orders, it seems as if large limit order submissions need to be very aggressive to trigger more cancellations. Alternatively, a very long time window needs to be studied for them to matter. In the very short run, the results are similar to those of the base model: less aggressive orders for the major currency pairs tends to trigger more, not fewer, limit order cancellations.

The empirical results for the split orders are also interesting. An informed trader would normally resort to an order-splitting strategy to disguise a larger amount. If successfully submitted (i.e. undetected by other market participants), such a strategy should not result in more order cancellations than normal. However, our empirical results show that the sign is positive and overwhelmingly strongly significant for the larger currency pairs (EUR/USD, USD/JPY, EUR/JPY and USD/MXN) for the $0.5,1$, 5, 10 and 60-second time windows, suggesting that order-splitting has a tendency to increase the number of order cancellations. An explanation for this pattern can probably be found in the market microstructure of EBS itself. Whereas order-splitting strategies have become increasingly common in the trading of a range of assets on numerous electronic platforms, the 1-million minimum order rule on EBS acts as an important floor for the 'race to the bottom'. A remarkably high proportion of all orders for the currency pairs above consist of precisely 1 million. In fact, the 
proportion of split orders (despite the fact that we use a very conservative definition) is higher than the combination of limit orders larger than 1 million for the three major currency pairs. In such a setting, it is quite plausible that a trader submitting a 2million limit order might be perceived as less informed or predatory than a trader submitting two 1-million limit orders at the same price and in less than 0.1 seconds after each other.

The results involving large orders (or large orders disguised as split orders) are, in themselves, puzzling, as we should expect that a large order automatically should be interpreted as information-rich, and hence act to result in a string of order cancellations on both sides of the market. Instead, the empirical results indicate that the market is either surprisingly slow in reacting to larger orders (highly unlikely), or that very large orders indeed are required to be submitted for the market to react. Split orders are very frequently submitted in the major currency pairs - yet seem to be detected and 'interpreted' as large orders. Alternatively, the results could be interpreted as if traders do not perceive amounts larger than 1 million as 'informed' or 'predatory' in the first instance.

\section{Concluding discussion}

In this paper, we have conducted an empirical investigation into market-specific and order-specific drivers of limit order cancellations in the FX spot market for three groups of currency pairs under stable market conditions. Using different time windows ranging from 0.1 seconds to 1 minute to capture the increasing prominence of algorithms on electronic trading platforms such as EBS, our findings can be summarised as follows.

The frequency distribution of limit order cancellations for all currency pairs studied (including those classified as emerging markets) seems to follow a power law. In other words, new limit order submissions tend to be followed by a chain reaction of cancellations, re-submissions and further limit order cancellations. This process largely takes place before a "human can blink" (within 0.2 seconds) and is largely 'normalised' within one second. Although the dataset used in our paper does not 
allow us to separate human from non-human limit order submissions and cancellations, is no doubt that all markets studied are populated with a significant portion of algorithmic traders.

With regards to the market-specific variables, three findings stand out. First, a deep market triggers more cancellations for most currency pairs (EUR/USD, USD/JPY, EUR/JPY, EUR/SEK, EUR/NOK and USD/TRY). However, for the large emerging market currency pairs (USD/MXN and USD/RUB), the pattern is the reverse: liquidity withdrawal becomes more prominent when the market is thin. Second, (human or algorithmic) traders withdraw liquidity as short-term volatility increases. However, this logical relationship is statistically stable only for the three major currency pairs (EUR/USD, USD/JPY and EUR/JPY). Third, a tighter bid-ask spread triggers more cancellations for the currency pairs with the highest turnover: EUR/USD, USD/JPY, EUR/JPY and USD/MXN. However, the relationship tends to be the opposite for the currency pairs with the lowest market turnover (EUR/SEK, EUR/NOK and USD/TRY). Here, less market liquidity (as proxied by the bid-ask spread) triggers a systematic series of submissions, cancellations and re-submissions at gradually more aggressive prices. We can only speculate why this is the case. One reason could be that they are more frequently traded on Reuters Dealing 3000 (EBS's closest competitor) rather than EBS. Anecdotal evidence from market participants suggests that Reuters Dealing 3000 is used as the primary electronic trading venue for EUR/SEK and EUR/NOK, whereas EBS is used as a secondary platform with less competitive prices. This might also partly explain why the normalisation process (as mentioned above) is considerably slower for the Scandinavian currency pairs in our study.

The results for the order-specific variables are also interesting. First, we would expect traders to be more inclined to cancel orders when observing and incoming order from the opposite side of the limit order book. However, for EUR/USD, USD/JPY, EUR/JPY, USD/MXN and USD/RUB this relationship only holds when studying very short time-horizons. When using longer time windows, the results show the opposite behaviour. The smaller currency pairs (EUR/SEK, EUR/NOK and USD/TRY) display such a pattern for all time windows used in the study. Thus, it appears as if limit orders in a range of currencies are systematically used to extract 
information about the dynamics and sensitivity of the limit order book on electronic trading platforms. Second, the impact of the limit order price aggressiveness seems to confirm the logic above for the major currency pairs. A less, not more, aggressive order prompts a higher number of cancellations. As the results from our extended model show, for EUR/USD, USD/JPY and EUR/JPY, a limit order needs to be large and very aggressive to trigger more cancellations. Alternatively, a very long time window needs to be studied for size and aggressiveness to show results similar to USD/MXN (the only currency pair that seems to be consistent with traditional market microstructure theory and conventional market wisdom in this regard). Third, our empirical study also shows that order-splitting strategies adopted by (algorithmic) traders to disguise larger amounts result in more cancellations than normal. Put differently, split orders are very frequently submitted in the major currency pairs - yet seem to be detected and classified as 'large' orders. Alternatively, the results could be interpreted as if traders do not perceive amounts larger than the minimum 1 million as 'informed' or 'predatory' in the first instance.

Overall, whereas EUR/USD, USD/JPY and EUR/JPY largely display similar patterns with regards to strategic order submission behaviour and liquidity withdrawal, the other five, however, have their own unique characteristics. More than $99.9 \%$ of the limit orders submitted in the two Scandinavian currency pairs have the minimum size of $€ 1$ million and the pattern of liquidity withdrawal is, perhaps, typical for a secondary electronic trading platform largely populated by non-human traders. The emerging market currency pairs, by contrast, are highly diverse. Whereas the results for the Turkish lira are relatively similar to those of the Scandinavian currencies (except for a normalisation process more akin to the major currencies), the Mexican peso seems to have the most 'logical' features according to market microstructure theory and market wisdom alike (for instance with regards to the number of order cancellations following large orders and a thin market). At the same time, however, the impact of some variables on the peso is similar to those on the major currency pairs (the bid-ask spread and orders submissions from the opposite side of the order book). The Russian rouble remains an outlier in our study. On the one hand, some results are similar to the currencies with a large daily turnover (such as the impact of orders from the opposite side of the order book). On the other hand, together with the Mexican peso, it is the only currency where a thin (rather than deep) market prompts 
more order cancellations. Importantly, USD/RUB is the only currency pair where large amounts are not only frequent but totally dominate the electronic order book.

There is no doubt that the eight FX spot markets in our study appear to be very liquid under stable market conditions. More than 3 million limit orders, worth over $\$ 5$ trillion in total, were submitted to EBS during just three trading days. Thus, when distinguished simply according to their speed, algorithmic traders could be seen as having a positive influence on the quality of the FX spot market. As Foucault et al. (2016) point out: directional high-frequency traders behave similarly to fast and informed speculators. If so, algorithmic traders would serve to enhance the price discovery process along the lines of Kyle (1985). However, being able to react faster, algorithmic traders have an advantage over traditional (human) market makers. The prevalence of what Harris (2013) refers to as harmful high-frequency trading activities ultimately boils down to how algorithmic traders have the ability to 'consume' limit orders submitted by traders who simply are not fast enough. Indeed, whether algorithmic traders ought to be regarded as liquidity providers or liquidity takers, the proportional decline in 'human' limit order submissions and limit order cancellations is arguable of greater concern for OTC markets such as FX. Whereas speed might not be considered harmful for the market in itself, it could act to crowd out the human market making function traditionally provided by banks. This might not be problematic under a stable market condition such as the one we have studied. However, algorithmic traders, and high-frequency traders among them, have no formal or informal market-making requirements. As Huh (2014) points out, this might become problematic in markets where such traders dominate the market making function, as liquidity might disappear precisely when liquidity is needed the most. This would have consequences for banks, end-users and central banks alike.

In sum, limit order cancellations in the FX spot market are a complex and multifaceted phenomenon. As this paper has shown, the drivers are influenced by different human and electronic market conventions and differ substantially depending on which currency pair is studied - and ultimately how many milliseconds are used to study the liquidity withdrawal process. 


\section{References}

ACI [The Financial Markets Association] (2015) The Model Code: The International Code of Conduct and Practice for the Financial Markets, Version February 2015.

Bershova, N. and Rakhlin, D. (2013) High-frequency trading and long-term investors: A view from the buy-side, Journal of Investment Strategies, 2, pp. 25-69.

Biais, B., Hillion, P. and Spatt, C. (1995) An Empirical Analysis of the Limit Order Book and the Order Flow on the Paris Bourse, Journal of Finance, 50 (5), pp. 16551689.

BIS (2011) High-frequency trading in the foreign exchange market.

BIS (2013) Triennial Central Bank Survey - Foreign exchange turnover in April 2013: preliminary global results, September 2013. Available from:

http://www.bis.org/publ/rpfx13fx.pdf [accessed 17 May 2017].

BIS (2017) The sterling 'flash event' of 7 October 2016.

Bjønnes, G. H., Rime, D. and Solheim, H. O. A. (2005) Liquidity provision in the overnight foreign exchange market, Journal of International Money and Finance, 24 (2), pp. 175-196.

Brogaard, J., Hendershott, T. and Riordan, R. (2014) High frequency trading and price discovery, Review of Financial Studies, 27, pp. 2267-2306.

Cao, C. Hansch, O. and Wang, X. (2009) The Information Content of an Open LimitOrder Book, Journal of Futures Markets, 29 (1), pp. 16-41.

CTFC (2014) CFTC Orders Five Banks to Pay over \$1.4 Billion in Penalties for Attempted Manipulation of Foreign Exchange Benchmark Rates, press release, 12 November. Available from: http://www.cftc.gov/PressRoom/PressReleases/pr7056-14 [accessed 17 May 2017].

Chan, L., and Lakonishok, J. (1995) The behavior of stock prices around institutional trades, Journal of Finance, 50, pp. 1147-74.

Cheung, Y.-W. and Chinn, M. D. (2001) Currency traders and exchange rate dynamics: a survey of the US market, Journal of International Money and Finance, 20, pp. 439-71.

Cheung, Y.-W. and Wong, C. Y.-P. (2000) A survey of market practitioners' views on exchange rate dynamics, Journal of International Economics, 51, pp. 401-19.

Conrad, J., Wahal, S. and Xiang, J. (2015) High-frequency quoting, trading, and the efficiency of prices, Journal of Financial Economics, 116, pp. 271-291.

Copeland, T. E. and Galai, D. (1983) Information effects on the bid-ask spread, Journal of Finance, 38, pp. 1457-1469. 
Engle, R. F., Ferstenberg, R. and Russell, J. R. (2012). Measuring and modeling execution cost and risk, Journal of Portfolio Management, 38 (2), pp. 14-28.

Evans, M. and Lyons, R. (2002) Order flow and exchange rate dynamics, Journal of Political Economy, 110, pp. 170-180

Fong, K. Y. L. and Liu, W. M. (2010) Limit order revisions, Journal of Banking and Finance, 34, pp. 1873-1885.

Foucault, T. (1999) Order flow composition and trading costs in a dynamic limit order market, Journal of Financial Markets, 2, pp. 99-134.

Foucault, T., Kadan, O. and Kandel, E. (2005) Limit order book as a market for liquidity, Review of Financial Studies, 18(4), pp. 1171-1217

Foucault, T., Moinas, S. and Theissen, E. (2007) Does Anonymity Matter in Electronic Limit Order Markets?, The Review of Financial Studies, 20 (5), pp. $1707-$ 1747.

Foucault, T., Hombert, J. and Rosu, I. (2016) News trading and speed, Journal of Finance 71, pp. 335-382.

Glosten, L. R. (19940 Is the Electronic Open Limit Order Book Inevitable? Journal of Finance, 49, pp. 1127-1161.

Goettler, R., Parlour, C. and Rajan, U. (2005) Equilibrium in a dynamic limit order market, Journal of Finance, 60, pp. 2149-2192.

Gopikrishnan, P., Plerou, V., Gabaix, X. and Stanley, H. (2000) Statistical properties of share volume traded in financial markets, Physical Review E, 62, pp. 4493-4496.

Griffiths, M., Smith, B., Turnbull, D. and White, R. (2000) The Costs and the Determinants of Order Aggressiveness, Journal of Financial Economics, 56, pp. 6588.

Hall, A. D. and Hautsch, N. (2006) Order Aggressiveness and Order Book Dynamics, Empirical Economics, 30, pp. 973-1005.

Hall, A. D. and Hautsch, N. (2007) Modelling the Buy and Sell Intensity in a Limit Order Book Market, Journal of Financial Markets, 10 (3), pp. 249-286.

Harris, L. (2013) What to do about high-frequency trading, Financial Analysts Journal 69(2), pp. 6-9.

Harris, L. and Hasbrouck, J. (1996) Market vs. Limit Orders: The SuperDOT Evidence on Order Submission Strategy, The Journal of Financial and Quantitative Analysis, 31 (2), pp. 213-231. 
Hollifield, B., Miller, R. A. and Sandås, P. (2004) Empirical Analysis of Limit Order Markets, The Review of Economic Studies, 71 (4), pp. 1027-1063.

Hasbrouck, J. and Saar, G. (2002) Limit orders and volatility on a hybrid market. Working paper, New York University.

Hendershott, T., Jones, C. M. and Menkveld, A. J. (2011) Does Algorithmic Trading Improve Liquidity?, The Journal of Finance, 66 (1), pp. 1-33.

Huh, Y. (2014) Machines vs. Machines: High Frequency Trading and Hard Information, Federal Reserve Board, Working Paper.

Keim, D., and Madhavan, A. (1995) Anatomy of the trading process: empirical evidence on the behavior of institutional traders, Journal of Financial Economics, 37, pp. 371-398.

Keim, D., and A. Madhavan, A. (1996) The upstairs market for large-block transactions: analysis and measurement of price effects, Review of Financial Studies, 9, pp. 1-36.

King, M. R. and Rime, D. (2010) The \$4 trillion question: what explains FX growth since the 2007 survey?, BIS Quarterly Review, December 2010.

Kyle, A. S. (1985) Continuous auctions and insider trading, Econometrica, 53, pp. $1315-1335$.

Liu, W-M. (2009) Monitoring and limit order submission risks, Journal of Financial Markets, 12, pp. 107-141.

Lo, I. and Sapp, S. G. (2010) Order Aggressiveness and Quantity: How Are They Determined in a Limit Order Market?, Journal of International Financial Markets, Institutions and Money, 20, pp. 213-237.

Lyons, R. (1997) A simultaneous trade model of the foreign exchange hot potato, Journal of International Economics, 42, pp. 275-298.

Maslow, S. and Mills, M. (2001) Price fluctuations from the order book perspective: empirical facts and a simple model, Physica A, 299, pp. 234-246.

Pérold, A. (1988) The implementation shortfall: paper versus reality, Journal of Portfolio Management, 14, pp. 4-9.

Ranaldo, A. (2004) Order Aggressiveness in Limit Order Book Markets, Journal of Financial Markets, 7 (1), pp. 53-74.

Rosu, I. (2009) A dynamic model of the limit order book, Review of Financial Studies, 22 (11), pp. 4601-4641.

Seppi, D. (1997) Liquidity provision with limit orders and a strategic specialist, Review of Financial Studies, 10, pp. 103-150. 
Stenfors, A. (2017) Bid-Ask Spread Determination in the FX Swap Market: Competition, Collusion or a Convention? Working Papers in Economics \& Finance, 2017-3, University of Portsmouth.

Stoll, H. R. (2014) High speed equities trading: 1993-2012, Asia-Pacific Journal of Financial Studies, 43, pp. 767-797.

Susai, M. and Yoshida, Y. (2014) Life-time of Limit Orders in the EBS Foreign Exchange Market. Working Paper, Nagasaki University and Shiga University.

Susai, M. and Yoshida, Y. (2015) We Missed It Again! Why Do So Many Market Orders in High Frequency FX Trading Fail to be Executed?, in G. N. Gregoriou (ed.) Handbook of High Frequency Trading. Amsterdam: Academic Press.

Vitale, P. (2006) A Market Microstructure Analysis of Foreign Exchange Intervention. ECB Working Paper Series, No. 629.

Yeo, W.Y. (2005) Cancellations of limit order. Working paper, National University of Singapore. 

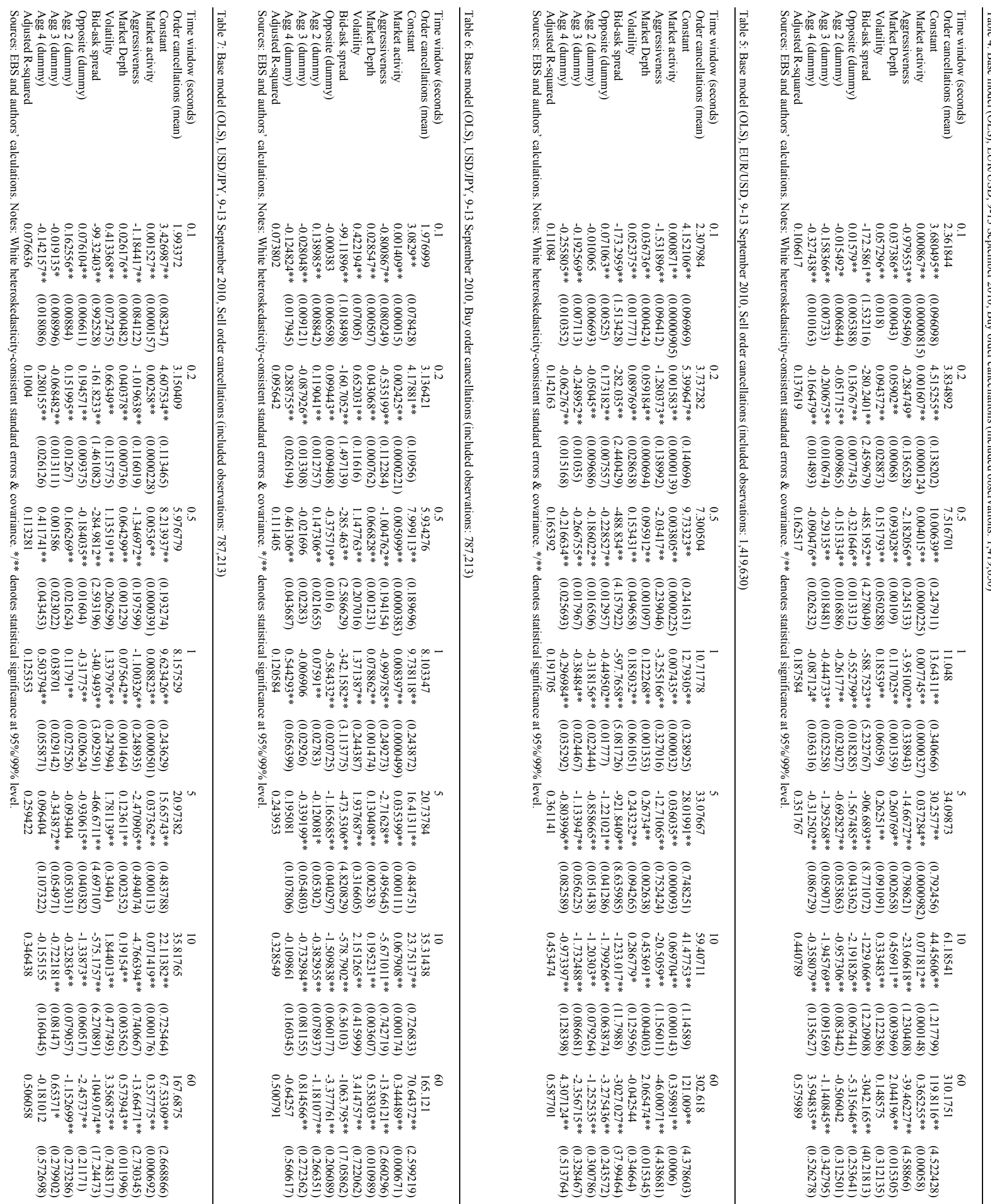

ondojojoojomno

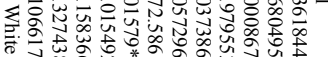

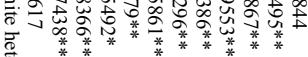

क्ष

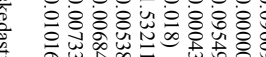

ह.

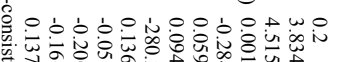
等

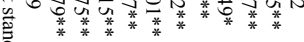

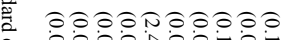

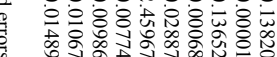

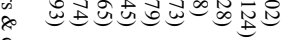

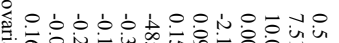

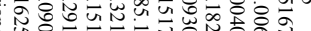

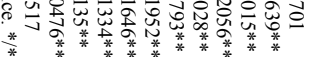

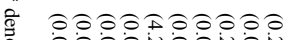

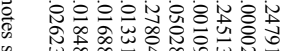

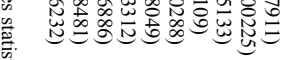

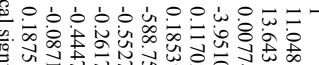

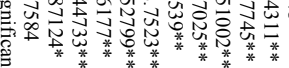

* àconacoso

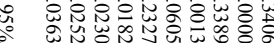

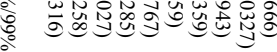

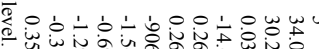

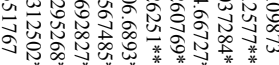

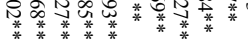

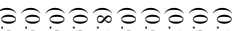

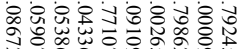

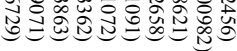

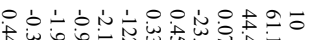

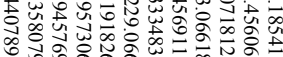

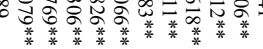

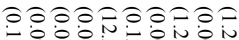

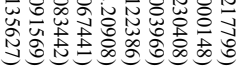

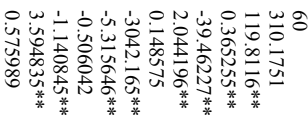

OOAOTOOFOA

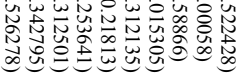




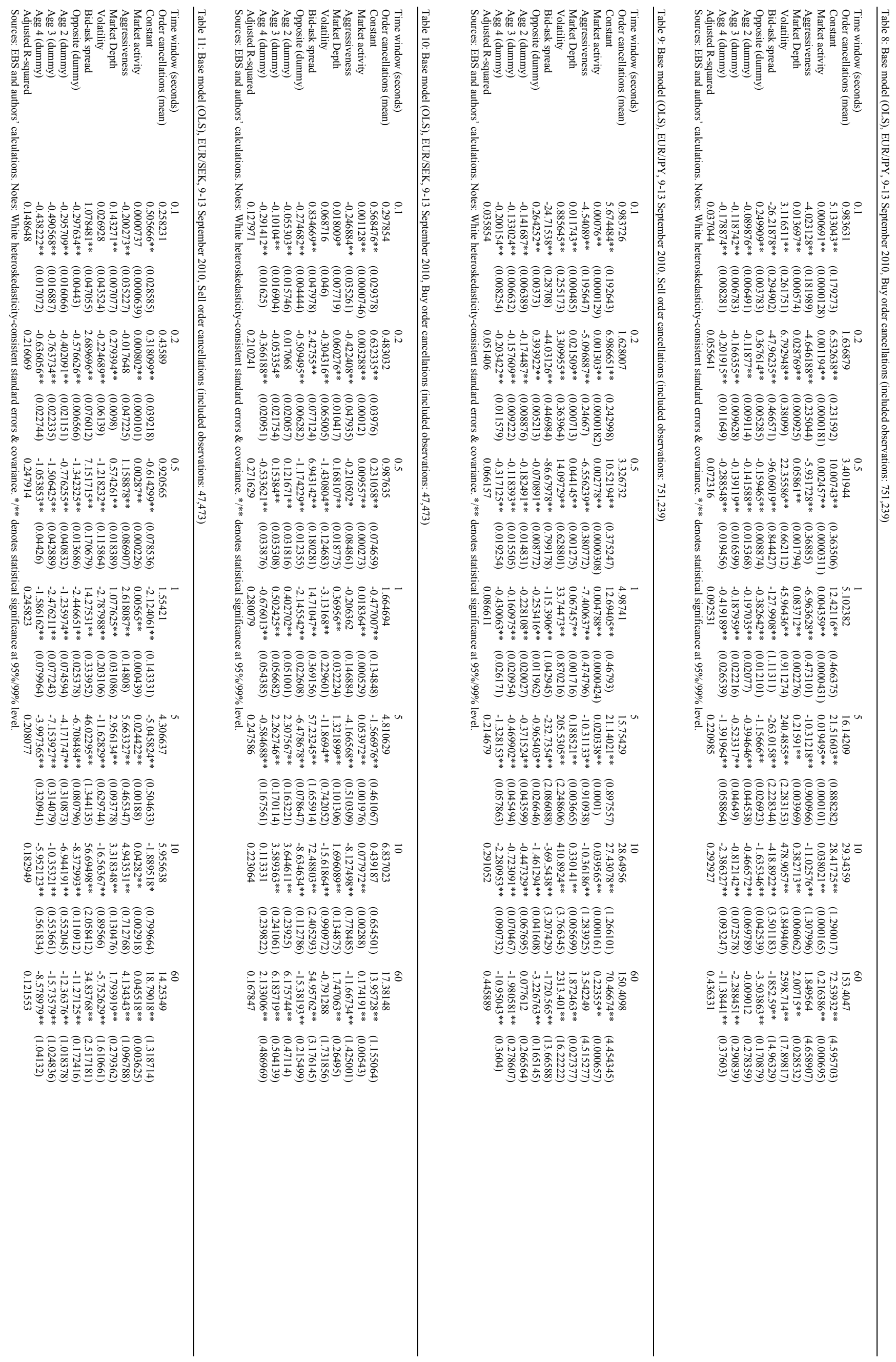




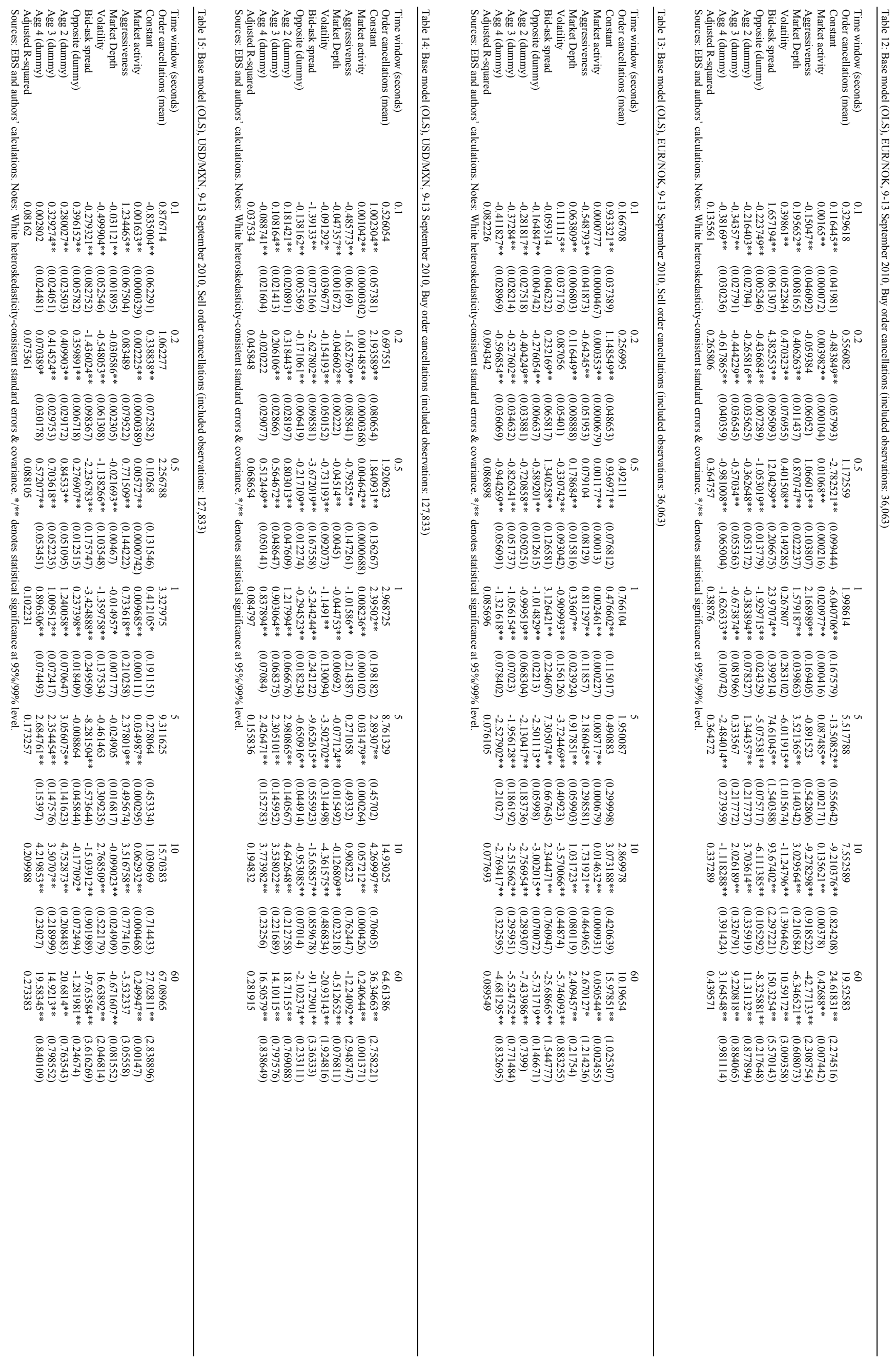




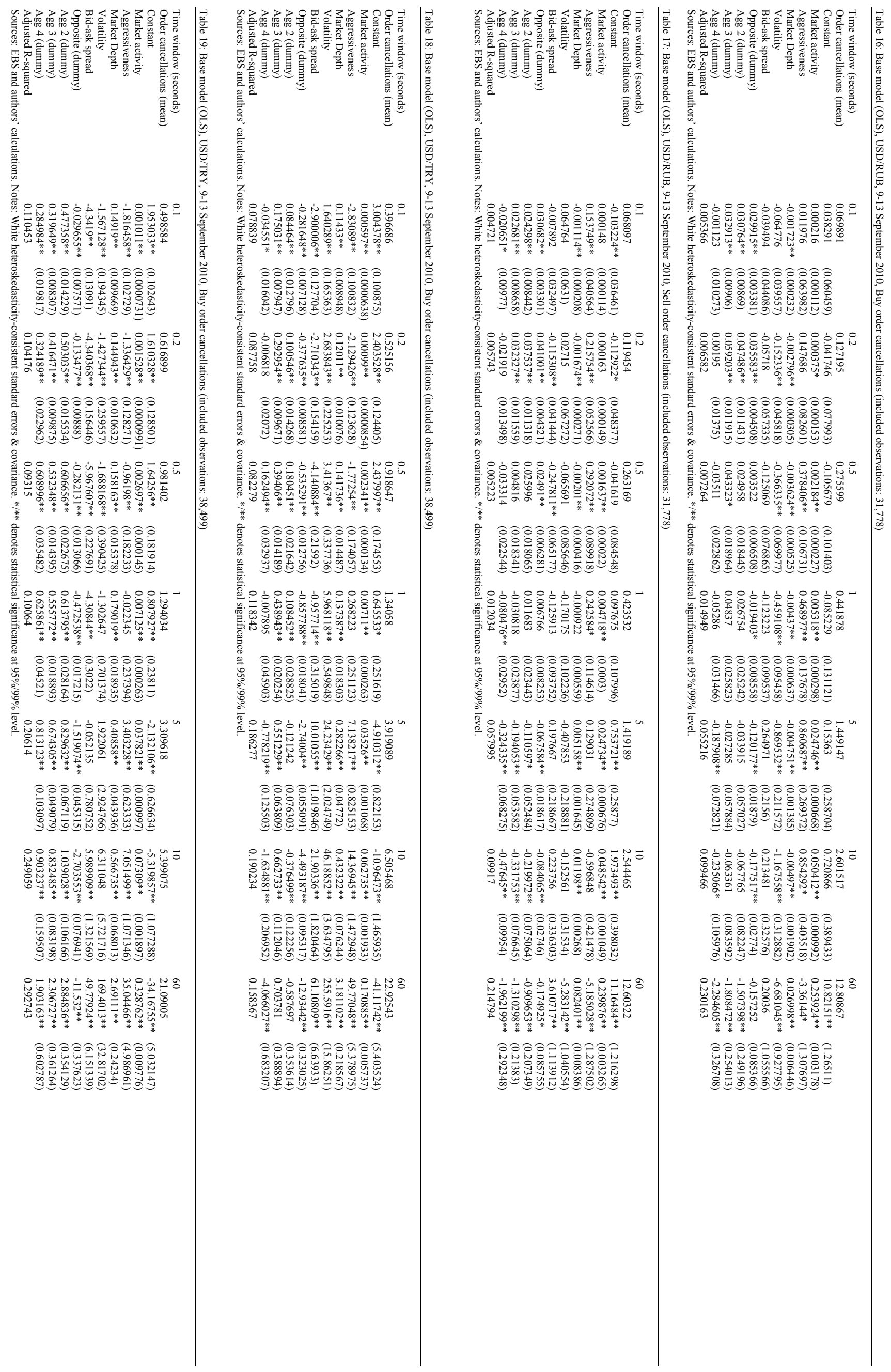




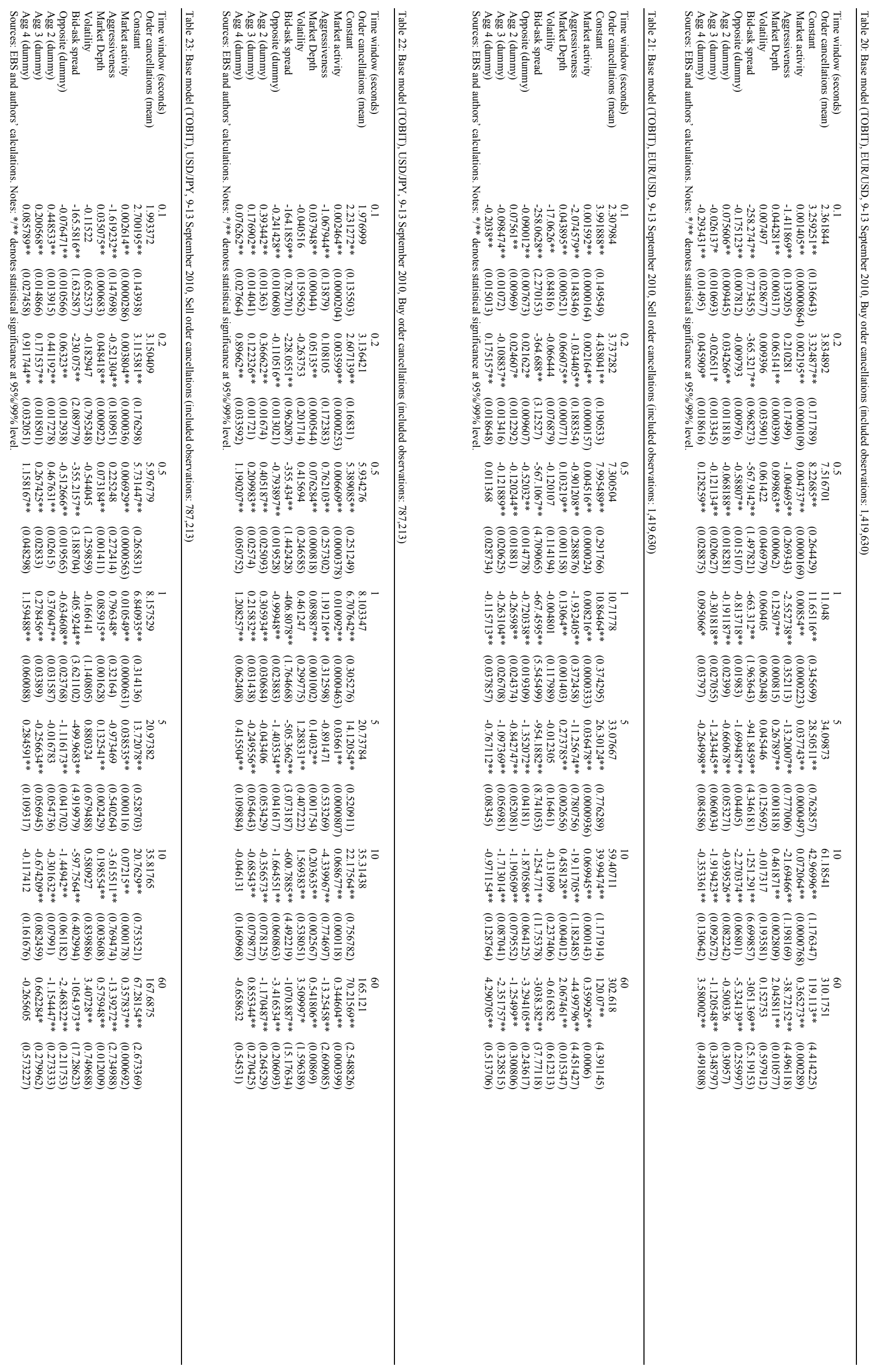




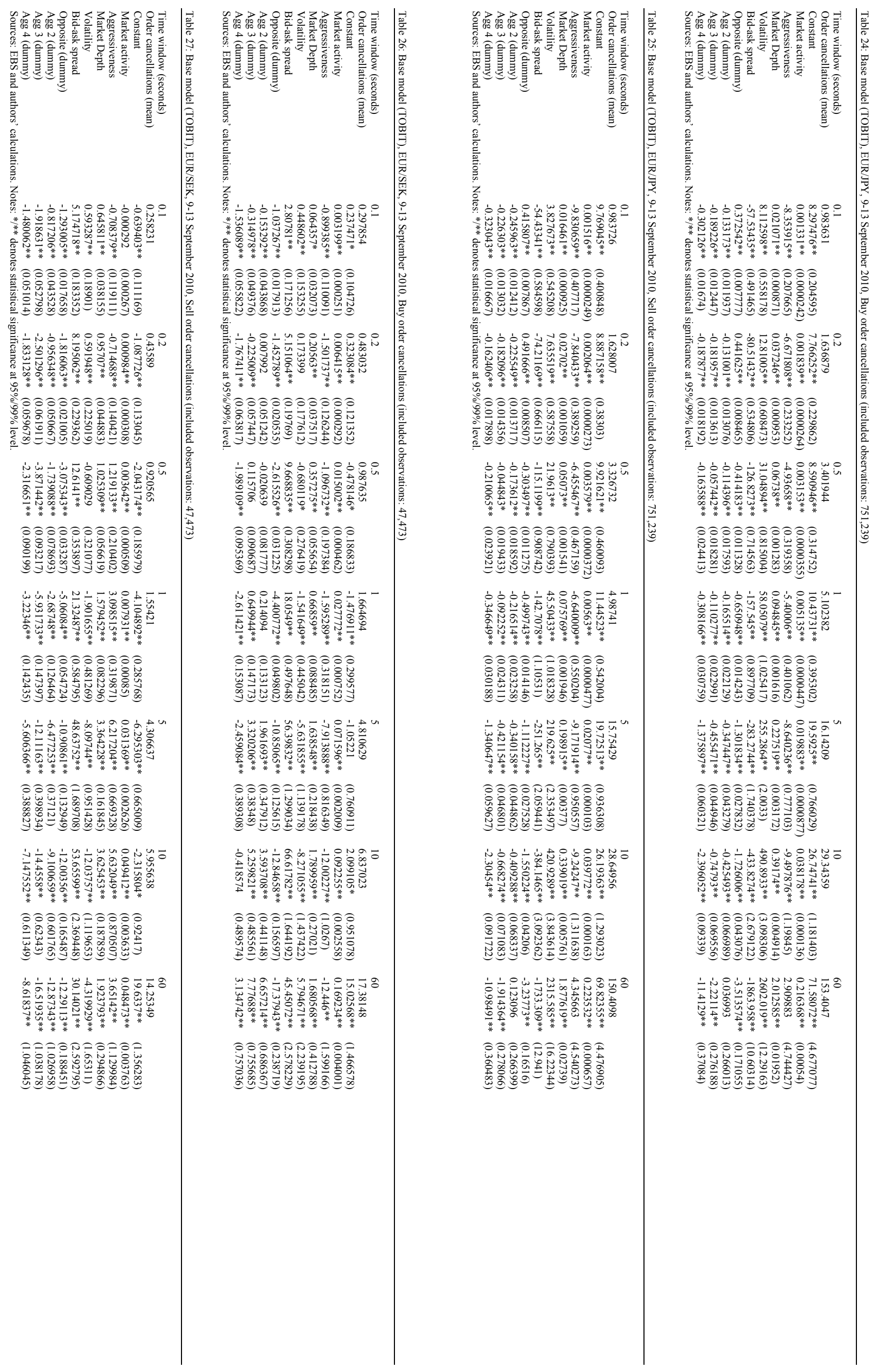




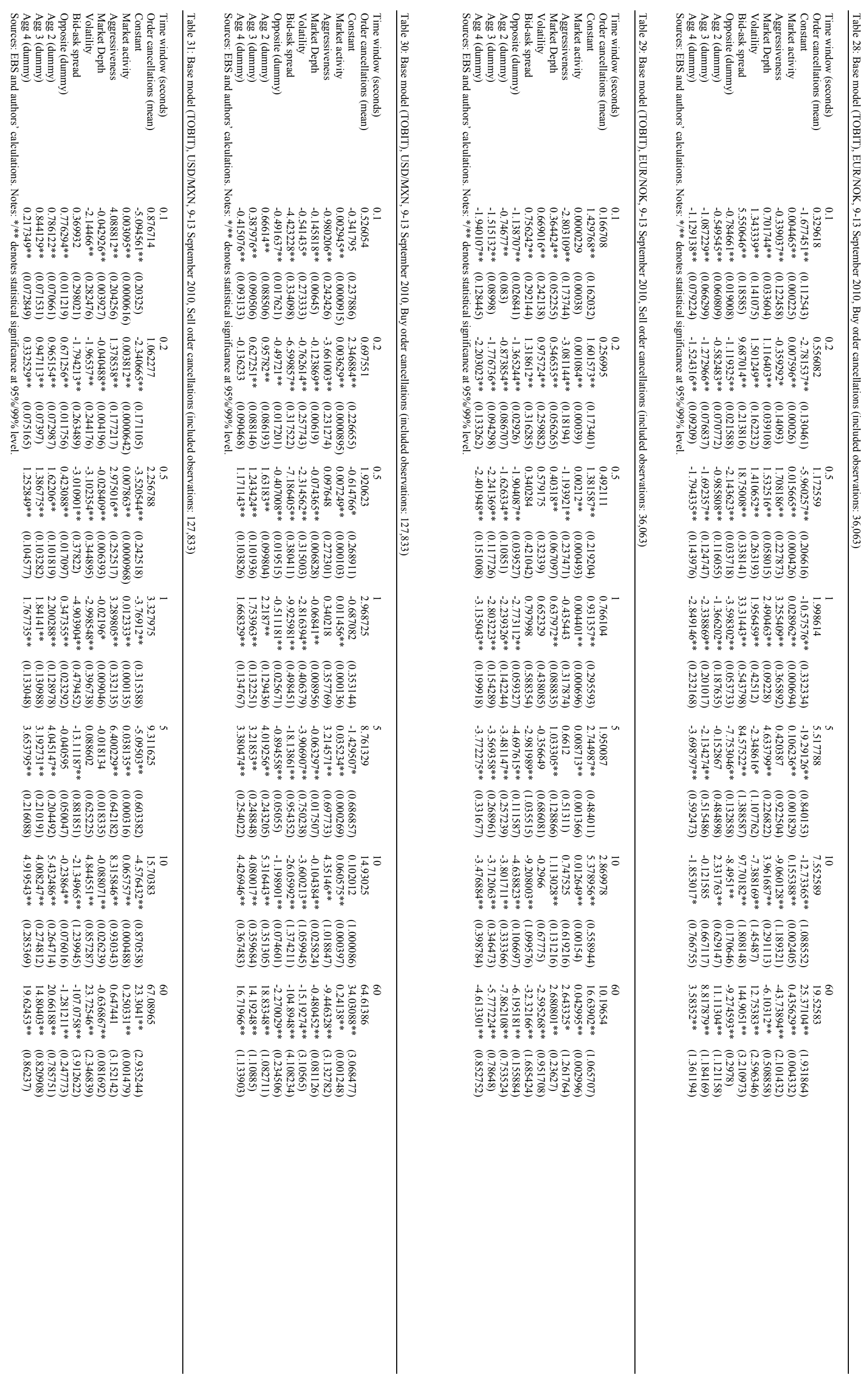









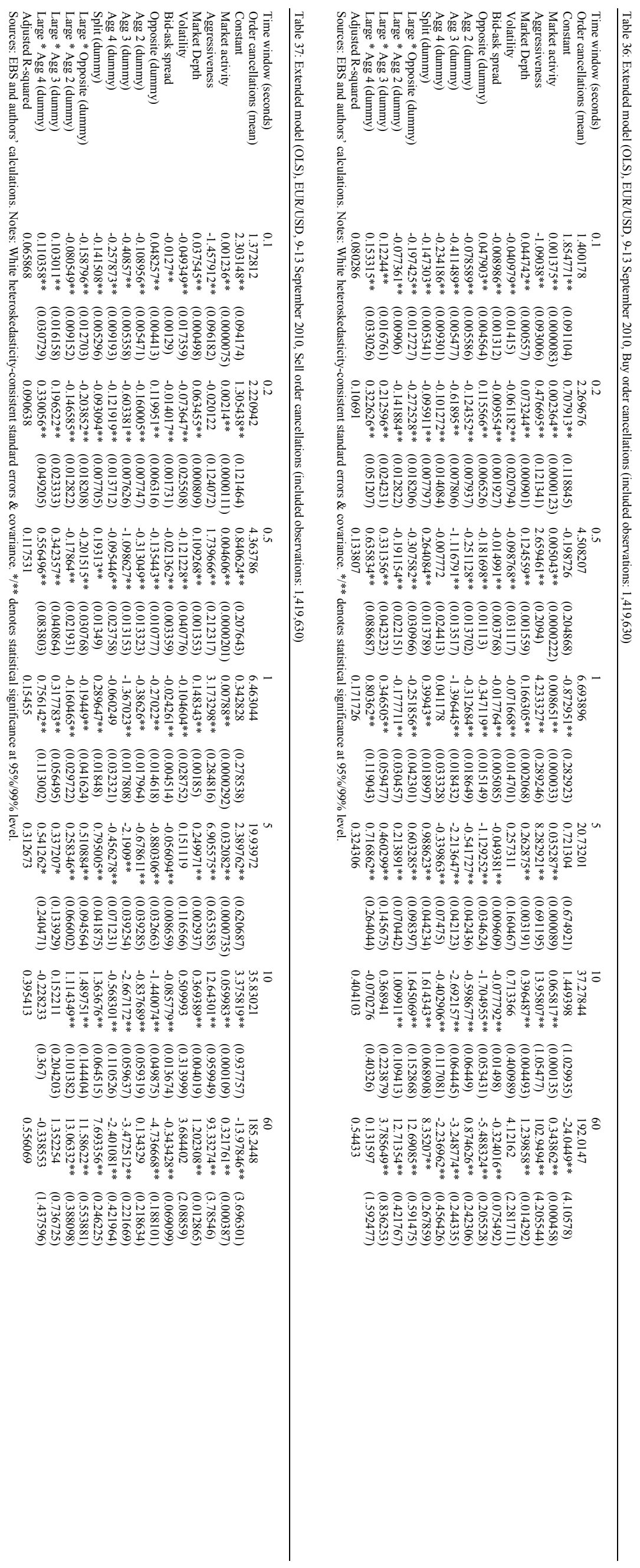




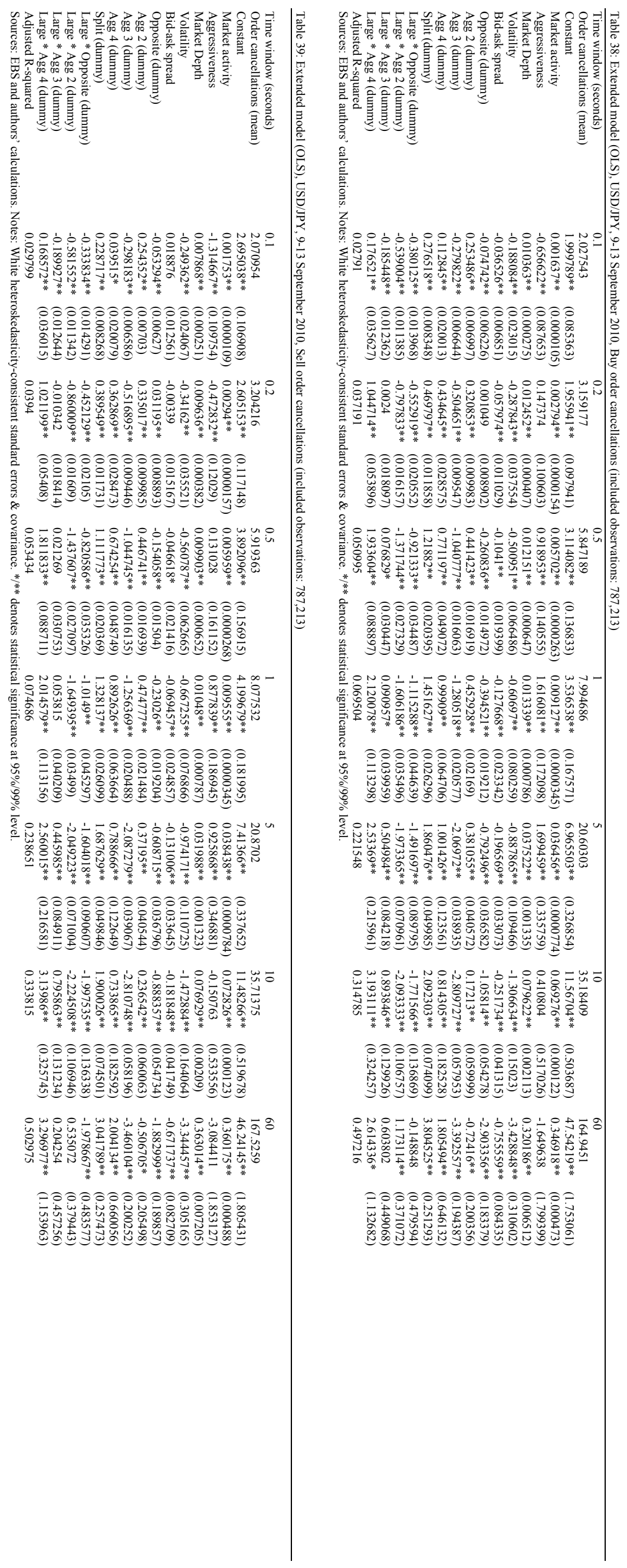




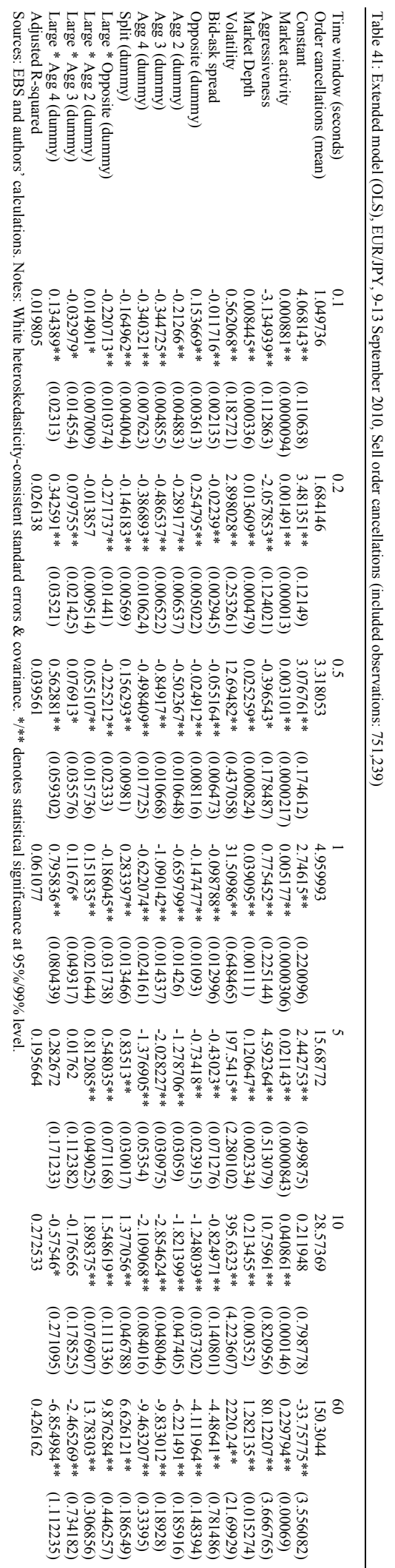

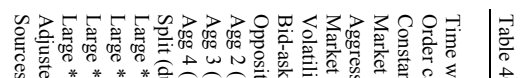

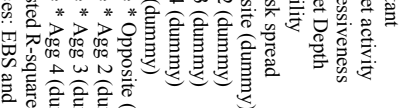

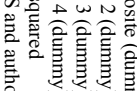
贾.

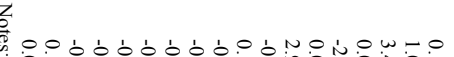

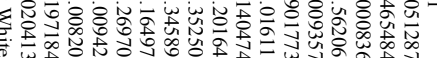

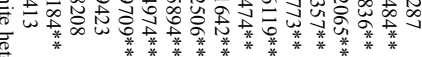

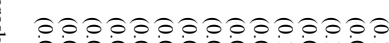

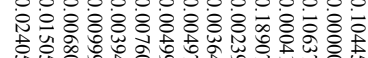

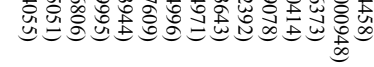

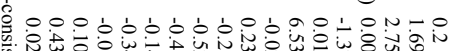

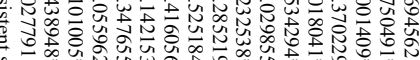

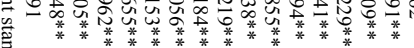

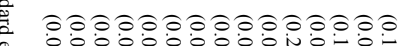

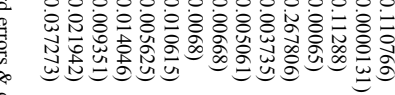

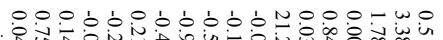

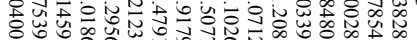

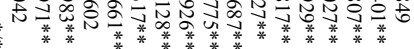

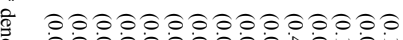

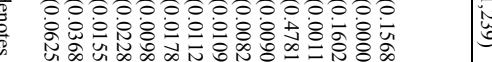

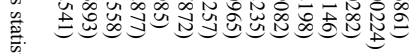

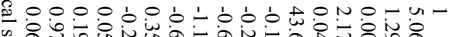

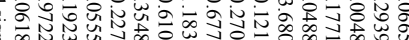

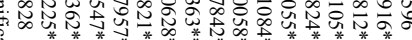

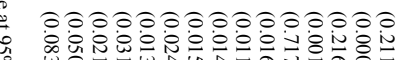

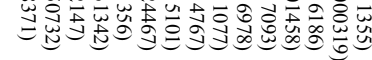

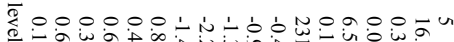

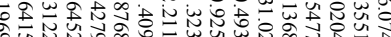

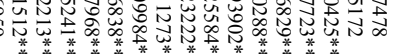

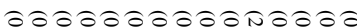

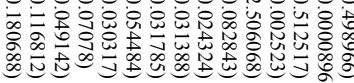

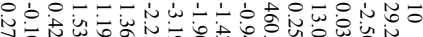

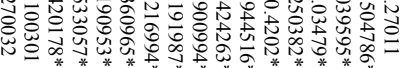

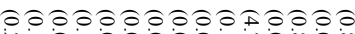

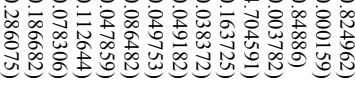

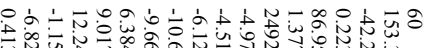

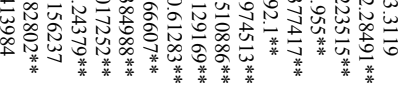

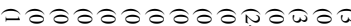

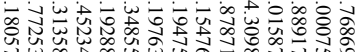

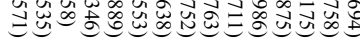




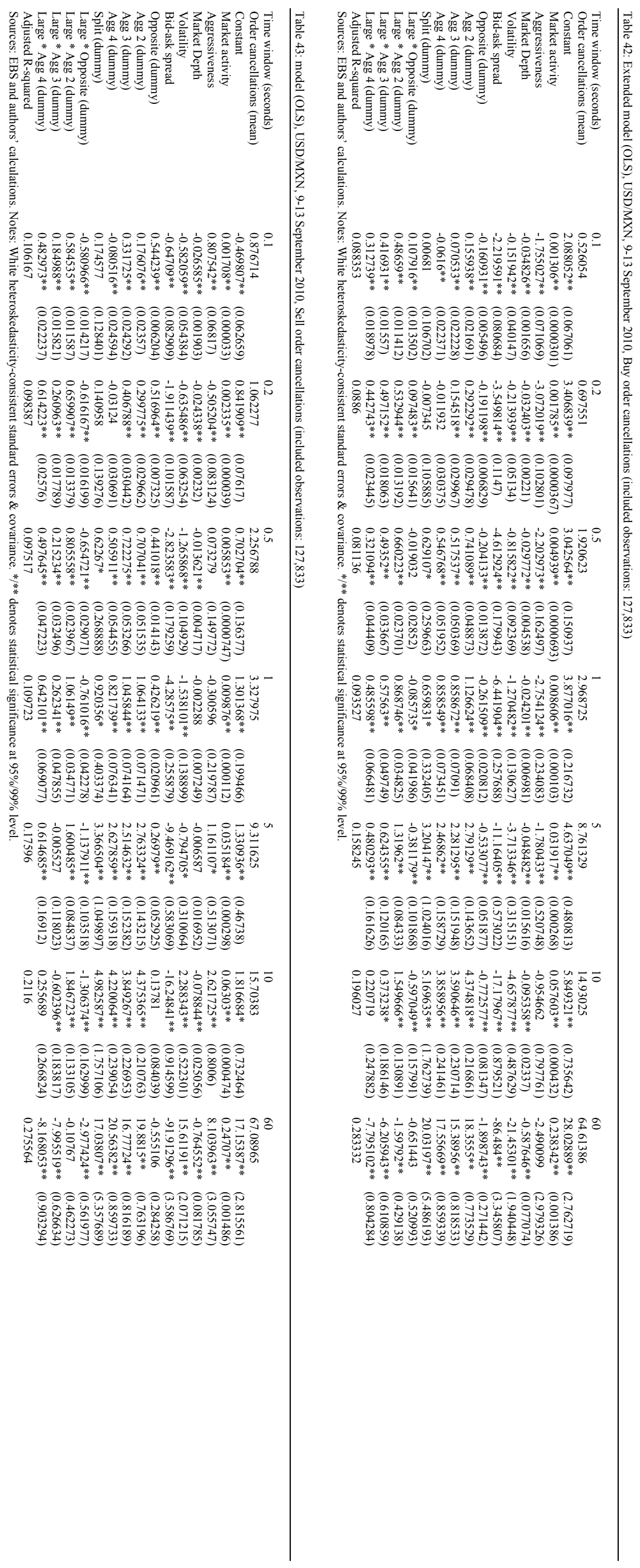




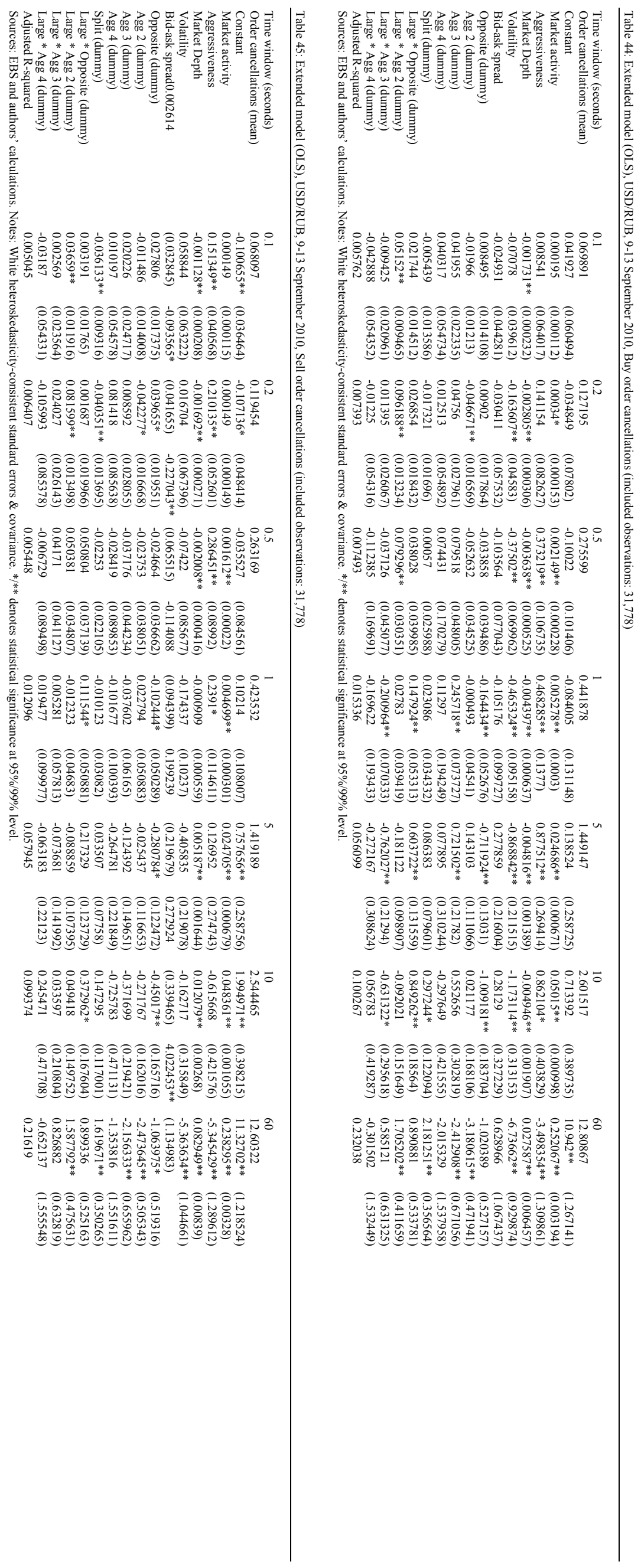




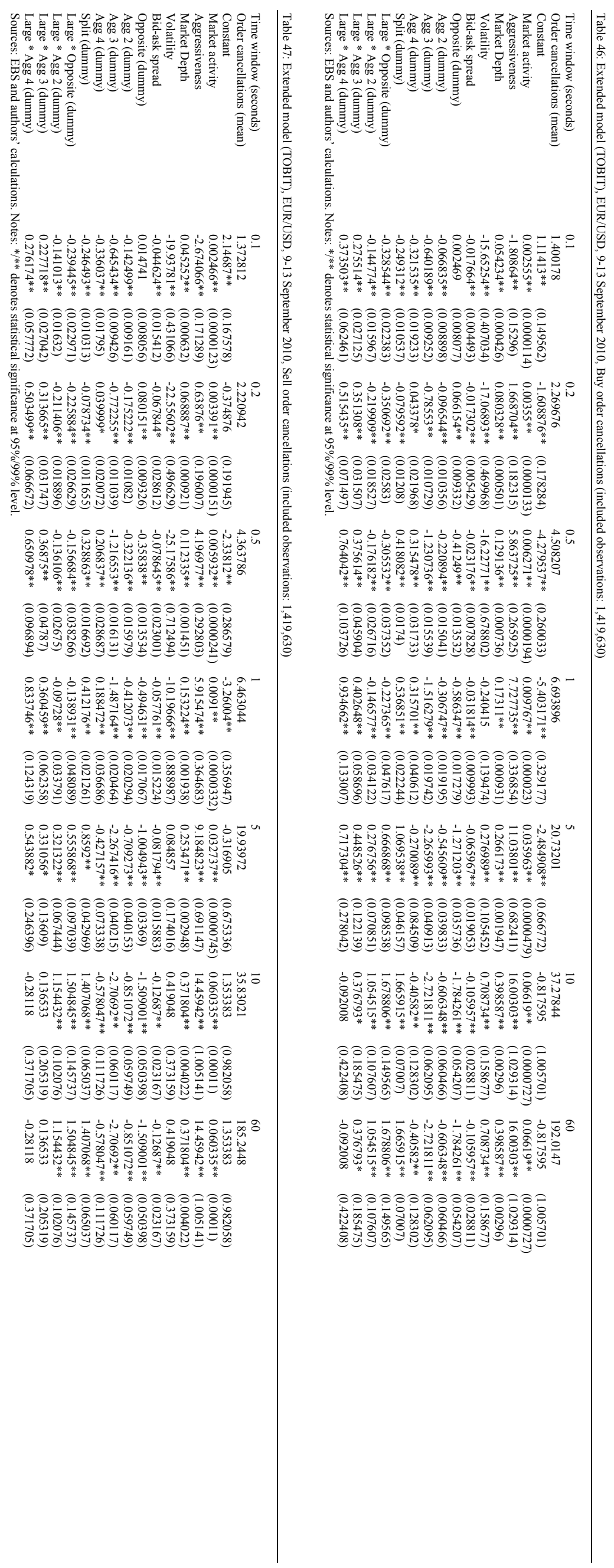



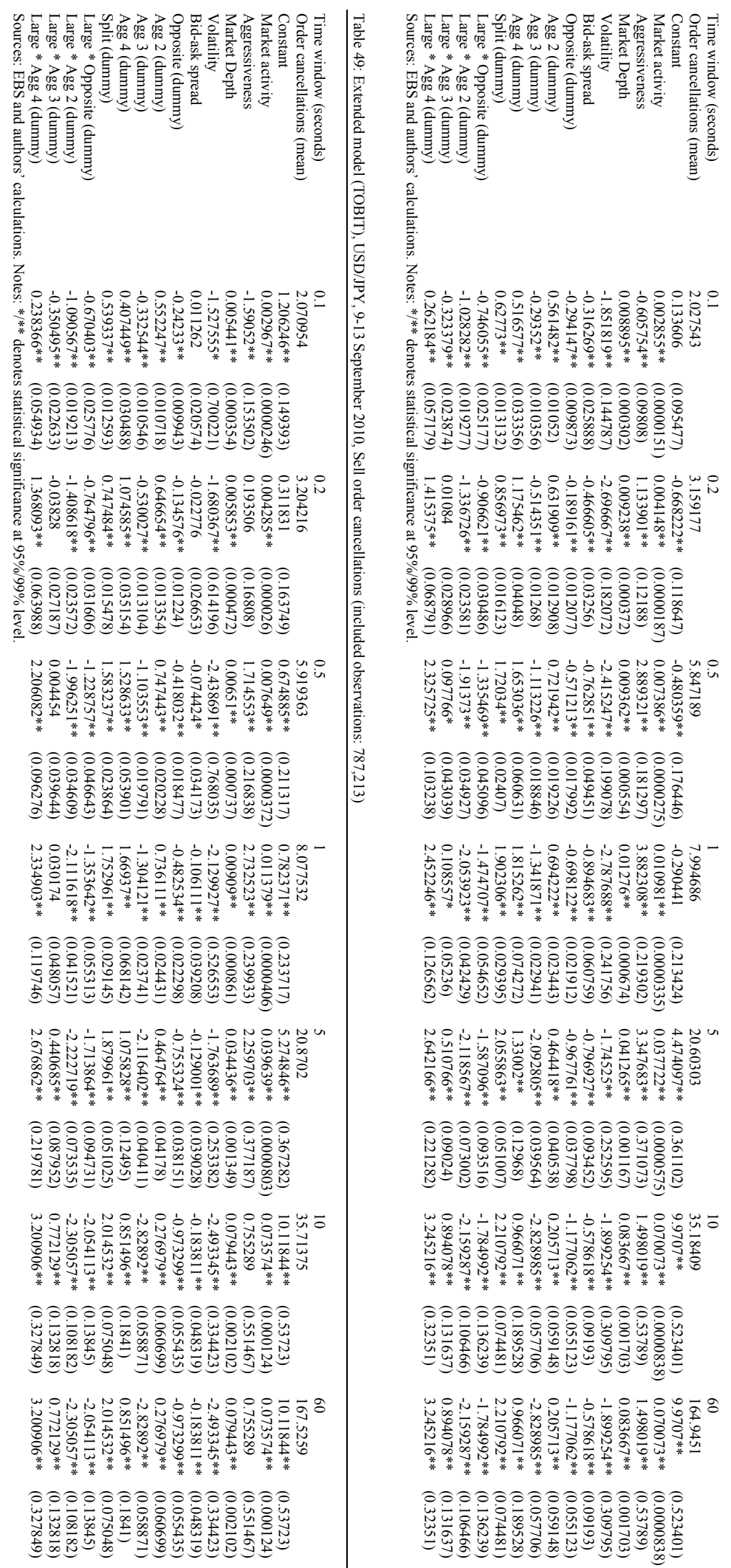

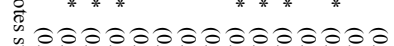

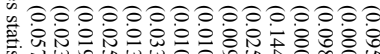

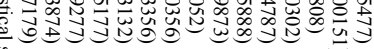

政.

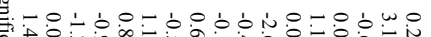

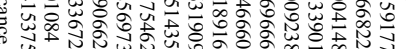

0
0
0
0

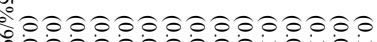

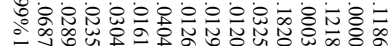

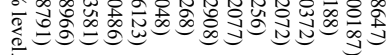

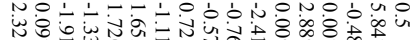

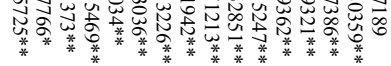

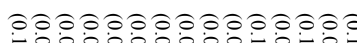

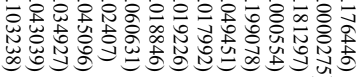

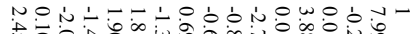

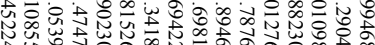

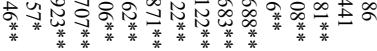

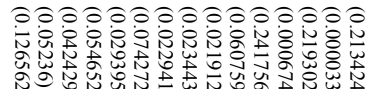

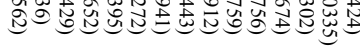

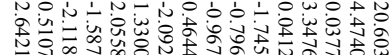

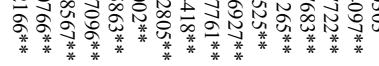

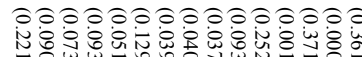

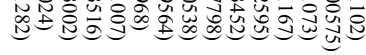

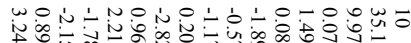

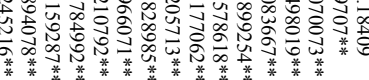

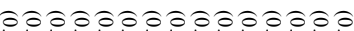

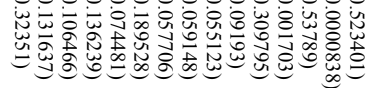

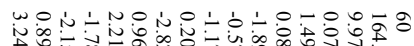

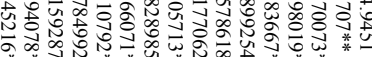

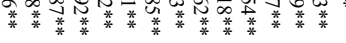

วอวอวอวอวอวอวอว

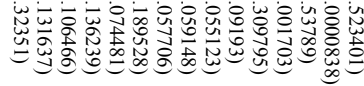




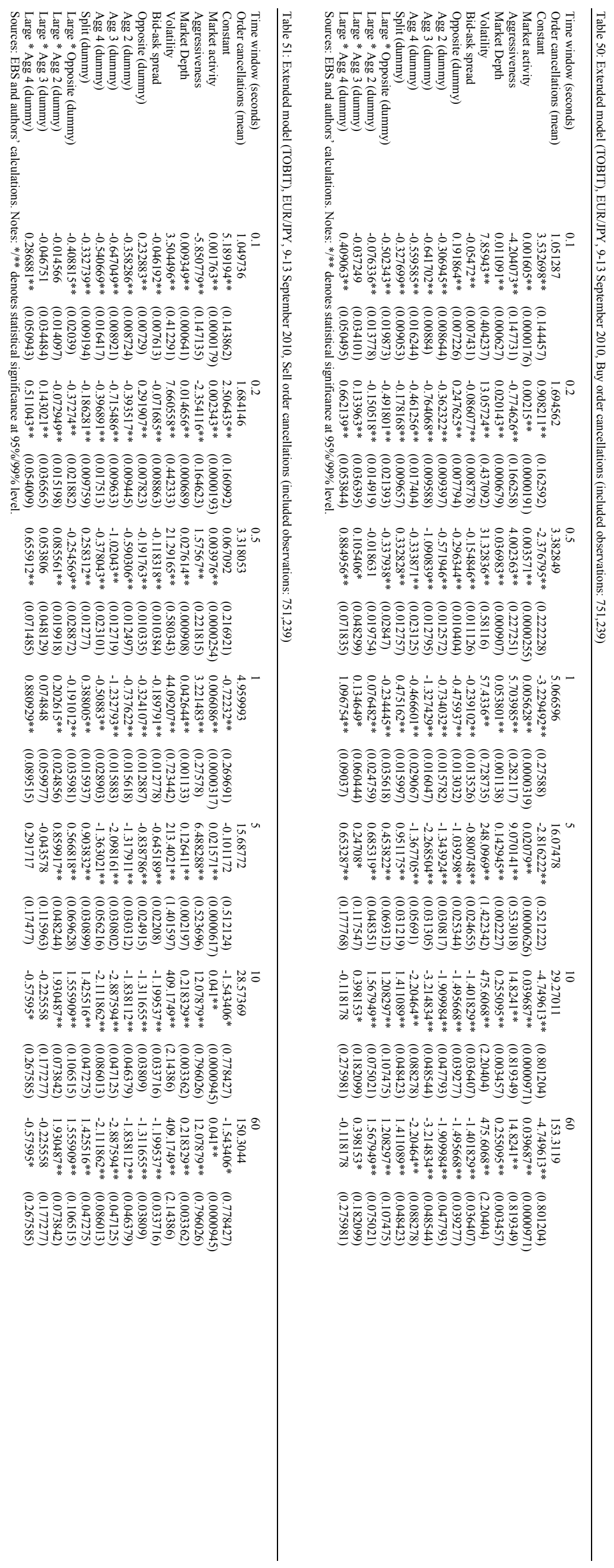




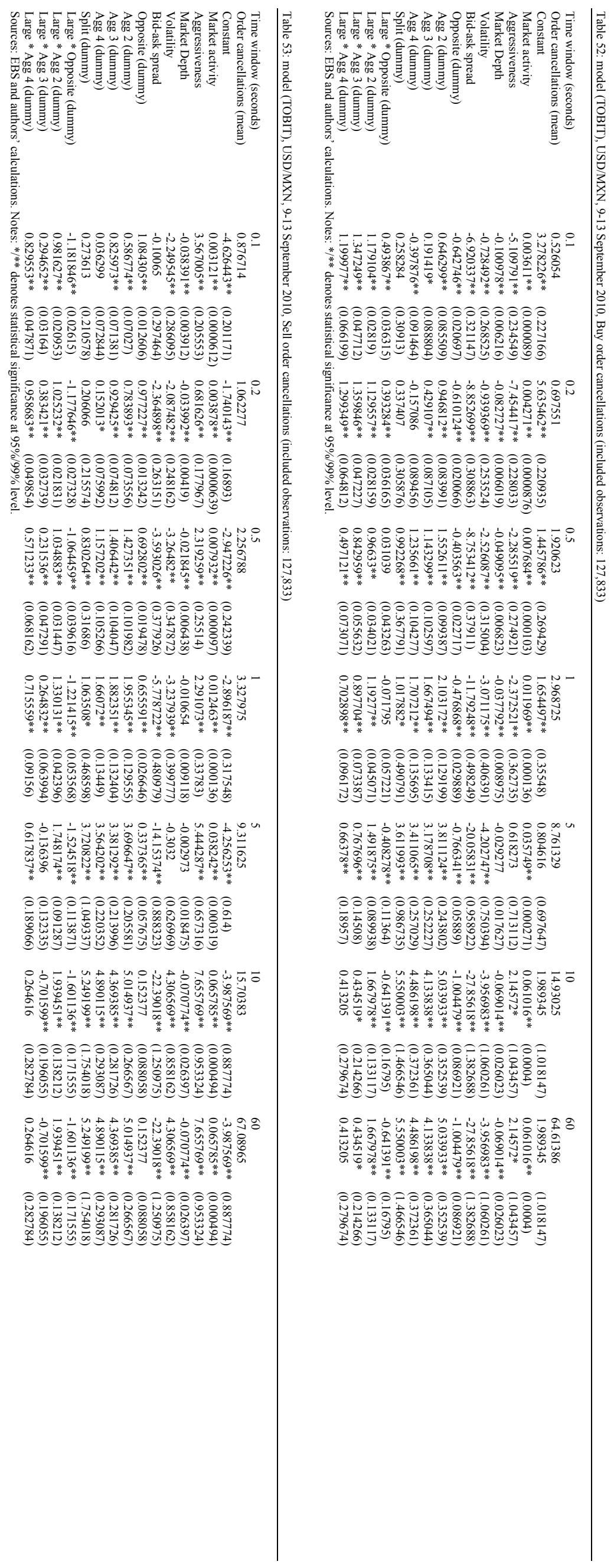




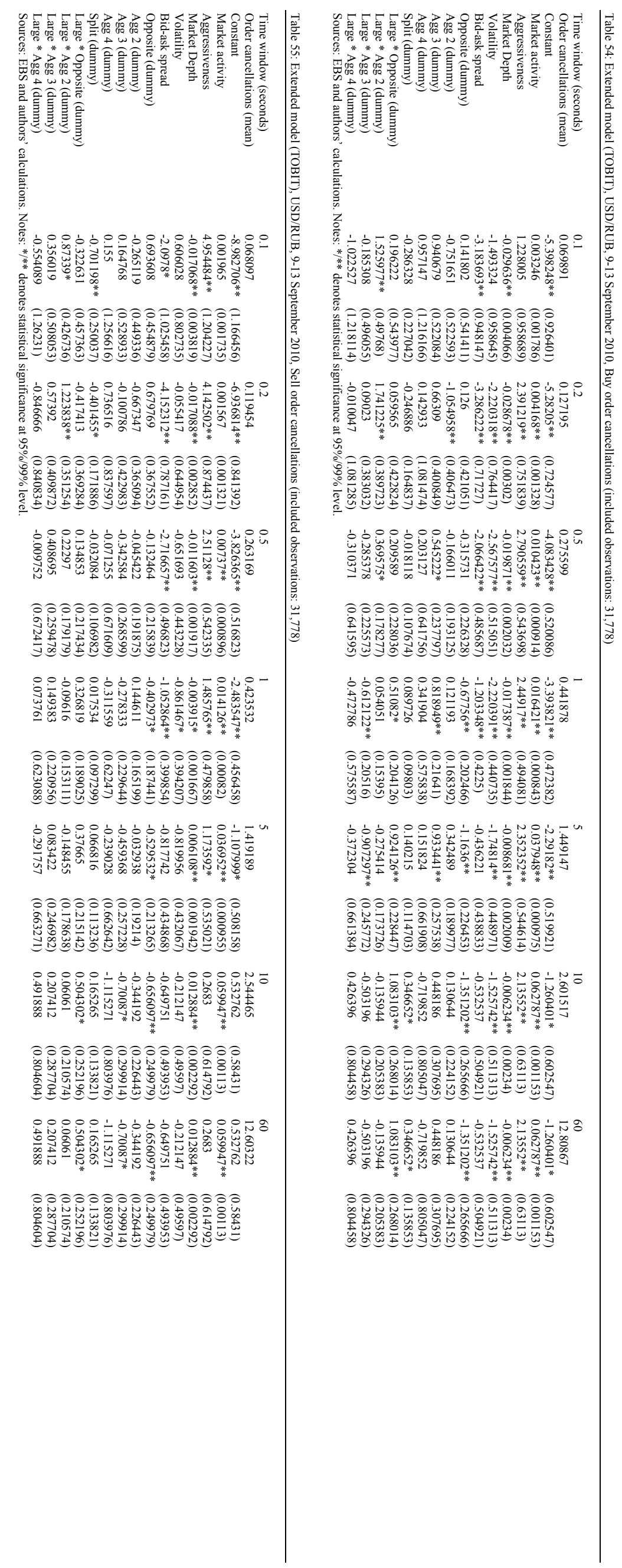

